\title{
Impact of the diurnal cycle of the atmospheric boundary layer on wind-turbine wakes: A numerical modelling study
}

\author{
4 Antonia Englberger · Andreas Dörnbrack
}

6 Received: DD Month YEAR / Accepted: DD Month YEAR

Abstract The wake characteristics of a wind turbine for different regimes occurring throughout the diurnal cycle are investigated systematically by means of large-eddy simulation. Idealised diurnal cycle simulations of the atmospheric boundary layer are performed with the geophysical flow solver EULAG over homogeneous and heterogeneous terrain. Under homogeneous conditions, the diurnal cycle significantly impacts the low-level wind shear and atmospheric turbulence. A strong vertical wind shear and veering with height occur in the nocturnal stable boundary layer and in the morning boundary layer, whereas the atmospheric turbulence is much larger in the convective boundary layer and in the evening boundary layer. The increased shear under heterogeneous conditions changes these wind characteristics, counteracting the formation of the night-time Ekman spiral. The convective, stable, evening, and morning regimes of the atmospheric boundary layer over a homogeneous surface as well as the convective and stable regimes over a heterogeneous surface are used to study the flow in a wind-turbine wake. Synchronized turbulent inflow data from the idealized atmospheric boundary-layer simulations with periodic horizontal boundary conditions are applied to the wind-turbine simulations with open streamwise boundary conditions. The resulting wake is strongly influenced by the stability of the atmosphere. In both cases, the flow in the wake recovers more rapidly under convective conditions during the day than under stable conditions at night. The simulated wakes produced for the nighttime situation completely differ between heterogeneous and homogeneous surface conditions. The wake characteristics of the transitional periods are influenced

A. Englberger

Institut für Physik der Atmosphäre, DLR Oberpfaffenhofen

E-mail: antonia.englberger@dlr.de

A. Dörnbrack

Institut für Physik der Atmosphäre, DLR Oberpfaffenhofen

E-mail: andreas.doernbrack@dlr.de 
by the flow regime prior to the transition. Furthermore, there are different wake deflections over the height of the rotor, which reflect the incoming wind direction.

Keywords Atmospheric boundary layer · Diurnal cycle · Large-eddy simulation · Turbulence · Wind-turbine wake

\section{Introduction}

A wind turbine operates in the atmospheric boundary layer $(\mathrm{ABL})$ where the diurnal variation of the flow has a significant impact on the wake structure. This interaction is poorly understood due to the complex structure of ABL turbulence during the day and night and in the transitional periods in response to external forcings as the diurnal heating cycle, frontal passages, precipitation, etc. The main sources of atmospheric turbulence that are relevant to wind energy are wind speed and directional shear (the change of wind speed and direction with height), buoyancy due to thermal stratification, and the interaction of the flow with surface heterogeneity caused by vegetation, buildings or complex terrain (e.g. Naughton et al., 2011; Emeis, 2013, 2014).

Thermal stratification has an impact on atmospheric turbulence. Based on thermal stratification and the dominant mechanism of turbulence production/destruction, the ABL is classified into stable, convective and neutral regimes (Stull, 1988). Stable atmospheric stratification results from a surface colder than the atmosphere due to outgoing infrared radiation at night, with shear as the main source of turbulence and negative buoyancy as main sink. Convective atmospheric stratification is caused by a warmer surface than the atmosphere due to solar irradiation during the day with positive buoyancy representing the main source of turbulence. Neutral atmospheric stratification occurs under very high wind speeds or during the transition between the stable boundary layer (SBL) at night and the convective boundary layer (CBL) during the day with less cooling or heating at the surface and with shear as major source of turbulence. These morning and evening transition periods are defined following Grimsdell and Angevine (2002) as the time period in which the sensible heat flux changes sign. The morning boundary layer and evening boundary layer, which are discussed in this paper, include the periods covering approximately half an hour before and after these transitions.

The diurnal cycle of the ABL has been studied since the 1970s. There are many observational and numerical studies regarding the SBL (Nieuwstadt, 1984; Carlson and Stull, 1986; Mahrt, 1998) and the residual layer (Balsley et al., 2008; Wehner et al., 2010). The CBL has also been investigated intensively with different focuses, e.g., on coherent structures (Schmidt and Schumann, 1989), on entrainment (Sorbjan, 1996; Sullivan et al., 1998; Conzemius and Fedorovich, 2007) and on shear (Moeng and Sullivan, 1994; Fedorovich et al., 2001; Pino et al., 2003). The first large-eddy simulation (LES) of a transition process in the ABL was performed by by Deardorff (1974a,b). Since 
then, many simulations considering the transitional phases have been performed on both the morning transition (Sorbjan, 2007; Beare, 2008) and the evening transition (Sorbjan, 1996, 1997; Beare et al., 2006; Pino et al., 2006). More recently, diurnal cycle simulation studies were conducted by Kumar et al. (2006) and Basu et al. (2008).

According to these studies, the diurnal cycle is prevalent in the wind profile; during the day, a logarithmic wind profile exists in the surface layer whereas a nearly constant wind speed and direction are prevalent above. During the night, the wind is lighter or calm at ground level. Aloft it can become supergeostrophic with wind speeds between $10 \mathrm{~m} \mathrm{~s}^{-1}$ to $30 \mathrm{~m} \mathrm{~s}^{-1}$ at roughly $200 \mathrm{~m}$ above ground level. This phenomenon is known as a low-level jet (LLJ) and is often accompanied by a rapid change in wind direction. Above the LLJ, the wind speed decreases to the geostrophic value. Furthermore, a diurnal cycle also exists in the turbulent intensity; in general, the CBL is very turbulent, whereas weaker and more sporadic turbulence exists in the SBL. In supergeostrophic situations, however, turbulence is generated at night by wind shear below the LLJ.

The heterogeneity of the surface also has an impact on atmospheric turbulence. Surface heterogeneity can be represented by temperature gradients via surface flux variations as in Kang et al. (2012) and Kang and Lenschow (2014), as well as by surface impacts like a modification of the roughness length as in Dörnbrack and Schumann (1993), Bou-Zeid et al. (2004), Calaf et al. (2014) or individual resolved roughness elements as in Belcher et al. (2003) and Millward-Hopkins et al. (2012). These studies reveal a considerable impact of surface heterogeneity on wind speeds and turbulence below the blending height, which is defined as the height at which the flow becomes horizontally homogeneous (Wieringa, 1976). Specifically, heterogeneity results in a transition from convective to shear-dominated regimes.

Atmospheric turbulence has an impact on the power produced by wind turbines, as well as on turbine fatigue loading and life expectancy (e.g. Hansen et al., 2012; Wharton and Lundquist, 2012; Sathe et al., 2013; Vanderwende and Lundquist, 2012; Dörenkämper et al., 2015). It affects the streamwise extension of the wake, the magnitude of the velocity deficit, and the turbulence intensity in the wake. The influence of atmospheric turbulence on these wake characteristics has been investigated in experimental studies considering different atmospheric stratifications. In general, the level of atmospheric turbulence is weaker (higher) in the stable (convective) case, resulting in a less rapid (more rapid) wake recovery and a larger (smaller) velocity deficit (Baker and Walker, 1984; Magnusson and Smedman, 1994; Medici and Alfredsson, 2006; Chamorro and Porté-Agel, 2010; Zhang et al., 2012, 2013; Tian et al., 2013; Iungo and Porté-Agel, 2014; Hancock and Pascheke, 2014; Hancock and Zhang, 2015).

Atmospheric stability has often been neglected in wind-energy studies, e.g. Porté-Agel et al. (2010); Calaf et al. (2010); Naughton et al. (2011); Wu and Porté-Agel (2011, 2012); Gomes et al. (2014). The entrainment of energy and momentum into the wake region and the resulting wake structure, however, 
strongly depend on the level of atmospheric turbulence in the upstream region of a wind turbine. Therefore, an accurate representation of the diurnal-cycledriven ABL flow is required to simulate realistic wake structures. Some recent LES studies investigate the impact of different atmospheric stratifications on the wake flow. Among others, an SBL has been considered by Aitken et al. (2014) and a CBL by Mirocha et al. (2014), with both studies performed using the Weather Research and Forecasting (WRF)-LES model. Bhaganagar and Debnath $(2014,2015)$ studied the effect of an SBL on the wake structure for a single wind turbine, while Dörenkämper et al. (2015) investigated the effect of the SBL on a wind farm. Mirocha et al. (2015) contrasted windturbine simulations under stable and convective conditions. Abkar and PortéAgel (2014) and Vollmer et al. (2016) investigated the effect of convective, neutral and stable stratifications on wake characteristics and Abkar et al. (2016) performed SBL and CBL simulations of a wind farm during a diurnal cycle. These studies reinforce the results of experimental studies, showing in a more rapid recovery of the flow in the wake for a higher level of atmospheric turbulence. Specifically, the flow in the wake has been shown to recover more rapidly under convective conditions than under stable conditions.

In the first part of this study, we perform a simulation of an idealized ABL over a homogeneous surface throughout a diurnal cycle with periodic horizontal boundary conditions. The diurnal cycle is simulated for two reasons; first, to investigate the diurnal variation of different atmospheric variables relevant to wind-energy research, and second, for use as a precursor simulation for the wind-turbine simulations. Therefore, $2 \mathrm{D}$ slices of the three wind components and the potential temperature are extracted at each time step from this precursor simulation.

In the second part of this study, the data of the idealized diurnal cycle simulation are used as synchronized atmospheric inflow conditions in simulations of a single wind turbine with open streamwise boundary conditions to investigate the impact of to investigate the impact of the CBL, the evening boundary layer (EBL), the SBL, and the morning boundary layer (MBL) on the wake structure. To our knowledge, this is the first study which also investigates the wake characteristics of a single wind turbine for the EBL and the MBL regimes.

In the third part of this study, we investigate the impact of an increased surface roughness on the wind-turbine wake structure for the CBL and the SBL regimes. For this purpose, we perform a 24-h idealized ABL simulation with a heterogeneous surface, represented by spatially distributed obstacles modelled as roughness elements. $2 \mathrm{D}$ slices of the three wind components and the potential temperature are extracted from the precursor simulation over a heterogeneous surface and applied in the wind-turbine simulations.

The outline of the paper is as follows: the numerical model, the external forcings during the ABL evolution, the setup of the diurnal cycle simulations, the interface between $\mathrm{ABL}$ and wind-turbine simulations, and the ABL and wind-turbine characteristics are described in Sect. 2. An investigation of the diurnal evolution of atmospheric variables relevant to wind-energy research for 
the idealized ABL simulation over a homogeneous surface follows in Sect. 3 . Wind-turbine simulations using this idealized ABL simulation over a homogeneous surface as a precursor simulation are presented in Sect. 4 for the different regimes throughout the diurnal cycles. In Sect. 5, an idealized ABL simulation over a heterogeneous surface and the corresponding wind-turbine simulations during the day and night are described. Conclusions are given in Sect. 6 .

\section{Numerical model framework}

\subsection{The numerical model EULAG}

The dry ABL flow as well as the flow through a wind turbine are simulated with the multiscale geophysical flow solver EULAG (Prusa et al., 2008; Englberger and Dörnbrack, 2017). The acronym EULAG refers to the ability of the model to solve the equations of motion in either a EUlerian (flux form) (Smolarkiewicz and Margolin, 1993) or in a semi-LAGrangian (advective form) (Smolarkiewicz and Pudykiewicz, 1992) mode. The geophysical flow solver EULAG is accurate in time and space to at least second-order (Smolarkiewicz and Margolin, 1998) and is well suited for massively-parallel computations (Prusa et al., 2008). It can be run in parallel up to a domain decomposition in three dimensions. A comprehensive description and discussion of the geophysical flow solver EULAG can be found in Smolarkiewicz and Margolin (1998) and Prusa et al. (2008).

For the numerical simulations conducted for this paper, the Boussinesq equations for a flow with constant density $\rho_{0}=1.1 \mathrm{~kg} \mathrm{~m}^{-3}$ are solved for the Cartesian velocity components $\mathbf{v}=(u, v, w)$ and for the potential temperature perturbations $\Theta^{\prime}=\Theta-\Theta_{e}$ (Smolarkiewicz et al., 2007),

$$
\frac{d \mathbf{v}}{d t}=-G \boldsymbol{\nabla}\left(\frac{p^{\prime}}{\rho_{0}}\right)+\mathbf{g} \frac{\Theta^{\prime}}{\Theta_{0}}+\mathcal{V}+\mathbf{M}-\alpha_{m} \mathbf{v}+\frac{\mathbf{F}_{W T}}{\rho_{0}}-2 \Omega\left(\mathbf{v}-\mathbf{v}_{e}\right)
$$

$$
\begin{aligned}
\frac{d \Theta^{\prime}}{d t} & =\mathcal{H}-\alpha_{h} \Theta^{\prime}-\mathbf{v} \nabla \Theta_{e}, \\
\nabla \cdot\left(\rho_{0} \mathbf{v}\right) & =0,
\end{aligned}
$$

where $\Theta_{0}$ represents the constant reference value. Height-dependent states $\psi_{e}(\mathrm{z})=\left(u_{e}(\mathrm{z}), v_{e}(\mathrm{z}), w_{e}(\mathrm{z}), \Theta_{e}(\mathrm{z})\right)$ enter Eqs. $1-3$ in the pressure gradient term, the buoyancy term, the Coriolis term, and as boundary conditions. These background states correspond to the ambient and environmental states. Initial conditions are provided for $u, v, w$, and the potential temperature perturbation $\Theta^{\prime}$ in $\psi=\left(u, v, w, \Theta^{\prime}\right)$. In Eqs. (1), (2) and (3), $d / d t, \boldsymbol{\nabla}$ and $\boldsymbol{\nabla} \cdot$ represent the total derivative, the gradient and the divergence, respectively. The quantity $p^{\prime}$ represents the pressure perturbation with respect to the background state and 
$\mathrm{g}$ the vector of acceleration due to gravity. The factor $G$ represents geometric terms that result from the general, time-dependent coordinate transformation (Wedi and Smolarkiewicz, 2004; Smolarkiewicz and Prusa, 2005; Prusa et al., 2008; Kühnlein et al., 2012). The subgrid-scale terms $\mathcal{V}$ and $\mathcal{H}$ symbolise viscous dissipation of momentum and diffusion of heat and $\mathbf{M}$ denotes the inertial forces of coordinate-dependent metric accelerations. $\mathbf{F}_{W T}$ corresponds to the turbine-induced force, implemented with the blade-element momentum method as a rotating actuator disc in the wind-turbine simulations (Englberger and Dörnbrack, 2017). The Coriolis force is the angular velocity vector of the earth's rotation with a Coriolis parameter of $f=1.0 \times 10^{-4} \mathrm{~s}^{-1}$. All the following simulations are performed with a turbulent kinetic energy (TKE) closure (Schmidt and Schumann, 1989; Margolin et al., 1999).

The obstacles in the ABL simulation with a heterogeneous surface are included via the immersed boundary method (Smolarkiewicz et al., 2007). This method mimics the presence of solid structures and internal boundaries by applying fictitious body forces $-\alpha_{m} \mathbf{v}$ in Eq. 1 and $-\alpha_{h} \Theta^{\prime}$ in Eq. 2. In the fluid away from the solid boundaries $\alpha_{m}$ and $\alpha_{h}$ are both zero, whereas $\alpha_{(m / h)}=1 / 2 \Delta t$ within the solid assuring the velocity approaches zero, with the timestep $\Delta t$. The immersed boundary method has been successfully applied in EULAG in Schröttle and Dörnbrack (2013), von Larcher and Dörnbrack (2014), and Gisinger et al. (2015).

In general, the geophysical flow solver EULAG owes its versatility to a unique design that combines a rigorous theoretical formulation in generalized curvilinear coordinates (Smolarkiewicz and Prusa, 2005) with non-oscillatory forward-in-time differencing for fluids built on the multidimensional positive definite advection transport algorithm, which is based on the convexity of upwind advection (Smolarkiewicz and Margolin, 1998; Prusa et al., 2008) and a robust, exact-projection type elliptic Krylov solver (Prusa et al., 2008). The flow solver has been applied to a wider range of scales simulating various problems including turbulence (Smolarkiewicz and Prusa, 2002), flow past complex or moving boundaries (Wedi and Smolarkiewicz, 2006; Kühnlein et al., 2012), gravity waves (Smolarkiewicz and Dörnbrack, 2008; Doyle et al., 2011) and solar convection (Smolarkiewicz and Charbonneau, 2013).

\subsection{Setup of the diurnal cycle simulations}

An idealized ABL simulation is performed with periodic horizontal boundary conditions on $512 \times 512$ grid points in the horizontal with a resolution of $5 \mathrm{~m}$ for $30 \mathrm{~h}$ representing a full diurnal cycle. The vertical resolution is $5 \mathrm{~m}$ in the lowest $200 \mathrm{~m}, 10 \mathrm{~m}$ up to $800 \mathrm{~m}$, and $20 \mathrm{~m}$ approaching the domain top at $2 \mathrm{~km}$. The simulation is initialised with a wind speed of $10 \mathrm{~m} \mathrm{~s}^{-1}$ in the zonal (east-west, streamwise) direction and zero for the meridional (north-south, spanwise, lateral) direction, and no vertical wind component. The ambient potential temperature $\Theta_{e}(z)$ of $300 \mathrm{~K}$ is constant up to $1 \mathrm{~km}$ and changes with height above according to a lapse rate of $10 \mathrm{~K} \mathrm{~km}^{-1}$. The temperature 
evolution of the sensible heat flux used in the idealized ABL simulation at the surface is shown in Fig. $1 a$ with a minimum sensible heat flux of $-10 \mathrm{~W} \mathrm{~m}^{-2}$ during the night and a maximum of $140 \mathrm{~W} \mathrm{~m}^{-2}$ at noon. It triggers the diurnal cycle by prescribing cooling at night and warming during the day and arises from values of the solar radiation during the day or the infrared irradiation at night divided by $\rho_{0}$ and the specific heat capacity at constant pressure and contributes to Eq. (2) via the subgrid-scale model. Furthermore, we do not include additional external forcings like large-scale subsidence or radiative cooling, because this simulation is not being directly compared with measurements and most of the presented analysis focuses on the operating height of a wind turbine $(\mathrm{z} \leq 200 \mathrm{~m})$, which is mostly unaffected by both mechanisms. This idealized ABL simulation is performed over a homogeneous surface with a drag coefficient of 0.1 , which enters the subgrid-scale momentum flux in Eq. 1.

In an additional simulation, a $24 \mathrm{~h}$ diurnal cycle is simulated over a heterogeneous surface, covered by obstacles representing for example individual patches of different land use or buildings. The individual obstacles have a size of $20 \mathrm{~m} \times 20 \mathrm{~m} \mathrm{x} 5 \mathrm{~m}$ and are separated from one another in the zonal and meridional directions by $20 \mathrm{~m}$, an arrangement similar to Belcher et al. (2003, Fig. 1). This setup results in a density of the surface of $25 \%$, which is considered to be appropriate for this investigation, as wind turbines are placed outside central city areas with a surface density of approximately $50 \%$ (Millward-Hopkins et al., 2012). The obstacles are implemented via the immersed boundary method described in Eqs. 1 and 2.

\subsection{Interface between ABL and wind-turbine simulations}

Wind-turbine simulations over homogeneous and heterogeneous terrain with open streamwise and periodic spanwise boundaries are performed for different stratifications lasting $1 \mathrm{~h}$ on a $512 \times 512 \times 64$ grid with a horizontal resolution of $5 \mathrm{~m}$ and a vertical resolution of $5 \mathrm{~m}$ in the lowest $200 \mathrm{~m}$ and $10 \mathrm{~m}$ above. The rotor of the wind turbine is located at $300 \mathrm{~m}$ in the $x$-direction and centred in the $y$-direction with a diameter $D$ and a hub height $z_{h}$, both $100 \mathrm{~m}$. In the heterogeneous wind-turbine simulations, it corresponds to a wind turbine located $300 \mathrm{~m}$ away from the obstacles in the precursor simulation.

The axial $\mathbf{F}_{x}$ and tangential $\mathbf{F}_{\Theta}$ turbine-induced forces $\left(\mathbf{F}_{W T}=\mathbf{F}_{x}+\right.$ $\left.\mathbf{F}_{\Theta}\right)$ in Eq. (1) are parametrized with the blade element momentum method as a rotating actuator disc with a nacelle, covering $20 \%$ of the blades. The forces account for different wind speeds and local blade characteristics and are parametrized with airfoil data from the 10-MW reference wind turbine from DTU (Technical University of Denmark) (Mark Zagar (Vestas), personal communication), whereas the radius of the rotor as well as the chord length of the blades are scaled to the rotor with a diameter of $100 \mathrm{~m}$. A detailed description of the wind-turbine parametrization and the applied smearing of 
the forces, as well as all values used in the wind-turbine parametrization are given in Englberger and Dörnbrack (2017, parametrization B).

Wind-turbine simulations using the idealized ABL simulations as precursor simulations are performed for four regimes in the homogeneous case and for two regimes in the heterogeneous one. These regimes are hereafter referred to as the CBL (12 h-13 h), EBL (18 h-19 h), SBL (24 h-25 h) and MBL $(29 \mathrm{~h}-30 \mathrm{~h})$ and likewise as $\mathrm{CBL}_{\text {het }}(12 \mathrm{~h}-13 \mathrm{~h})$ and $\mathrm{SBL}_{\text {het }}(24 \mathrm{~h}-25 \mathrm{~h})$.

For the synchronized coupling between the ABL and the wind-turbine simulations, the initial fields of $\psi$ at $t=12 \mathrm{~h}, 18 \mathrm{~h}, 24 \mathrm{~h}$, and $29 \mathrm{~h}$ for the homogeneous wind-turbine simulations and at $t=12 \mathrm{~h}$ and $24 \mathrm{~h}$ for the heterogeneous wind-turbine simulations, as well as the $2 \mathrm{D}$ inflow fields of $\psi$ at each timestep of the following one hour of the wind-turbine simulations are provided by the corresponding idealized ABL simulation. Further, the horizontal averages of the respective initial conditions of $\psi$ are taken as background fields $\psi_{e}$. At each timestep of the wind-turbine simulation, the two dimensional $y$ - $z$ slices contribute to the upstream values of $\psi$ at $i=1$, the left-most edge of the numerical domain at $x=0$. This approach to handling the interface between the ABL and wind-turbine simulations is similar to techniques used by Kataoka and Mizuno (2002), Naughton et al. (2011), Witha et al. (2014), and Dörenkämper et al. (2015).

\subsection{ABL and wind-turbine characteristics}

This paper investigates the following characteristics of the ABL and the windturbine wakes:

- The budget of the resolved mean TKE of the ABL

$$
\bar{e}=\frac{1}{2}\left(\overline{u^{\prime \prime 2}}+\overline{v^{\prime \prime 2}}+\overline{w^{\prime \prime 2}}\right),
$$

is calculated at each height level according to Stull (1988)

$$
\begin{aligned}
& \underbrace{\frac{\partial \bar{e}}{\partial t}}_{\text {Storage St }}=-\underbrace{\left(\overline{u^{\prime \prime} w^{\prime \prime}} \frac{\partial \bar{u}}{\partial z}+\overline{v^{\prime \prime} w^{\prime \prime}} \frac{\partial \bar{v}}{\partial z}\right)}_{\text {Shear } S}+\underbrace{\frac{g}{\Theta_{0}} \overline{w^{\prime \prime} \Theta^{\prime \prime}}}_{\text {Buoyancy Production } B} \\
& -\underbrace{\frac{\partial \overline{w^{\prime \prime} e^{\prime \prime}}}{\partial z}}_{\text {Turbulent Transport T }}-\underbrace{\epsilon}_{\text {Dissipation } D} .
\end{aligned}
$$

In this representation, $u^{\prime \prime}, v^{\prime \prime}, w^{\prime \prime}, \Theta^{\prime \prime}, p^{\prime \prime}$, and $e^{\prime \prime}$ are the turbulent fluctuations of the velocity components $u, v, w$, the potential temperature $\Theta$, the pressure $p$ and the resolved turbulent kinetic energy e. $\Theta_{0}$ is the reference potential temperature at the ground. $\epsilon$ represents the dissipation rate and is calculated as the residual from all other contributions. The overlines in 
Eq. (4) indicate a temporal $(1 \mathrm{~h})$ and an area (horizontal domain size) average. Here, $\xi^{\prime \prime}=\xi-<\xi(z)>_{x, y}$, whereas $\xi^{\prime}=\xi-\xi_{e}$. For all variables except for $\xi=\Theta, \xi^{\prime \prime}=\xi^{\prime}$.

- The spatial distribution of the time-averaged streamwise velocity $\overline{u_{i, j, k}}$, the streamwise velocity ratio

$$
V R_{i, j, k} \equiv \frac{\overline{u_{i, j, k}}}{\overline{u_{i_{1}, j, k}}},
$$

and the streamwise velocity deficit

$$
V D_{i, j, k} \equiv \frac{\overline{u_{i_{1}, j, k}}-\overline{u_{i, j, k}}}{\overline{u_{i_{1}, j, k}}}
$$

as they are related to the power loss of a wind turbine.

- The total turbulent intensity

$$
I_{i, j, k}=\frac{\sqrt{\frac{1}{3}\left(\sigma_{u_{i, j, k}}^{2}+\sigma_{v_{i, j, k}}^{2}+\sigma_{w_{i, j, k}}^{2}\right)}}{\overline{u_{i, j, k_{h}}}},
$$

with $\sigma_{u_{i, j, k}}=\sqrt{\overline{\overline{u_{i, j, k}^{\prime 2}}}}, \sigma_{v_{i, j, k}}=\sqrt{\overline{v_{i, j, k}^{\prime 2}}}$, and $\sigma_{w_{i, j, k}}=\sqrt{\overline{\overline{w_{i, j, k}^{\prime 2}}}}$, as well as $u_{i, j, k}^{\prime}=u_{i, j, k}-\overline{u_{i, j, k}}, v_{i, j, k}^{\prime}=v_{i, j, k}-\overline{v_{i, j, k}}$, and $w_{i, j, k}^{\prime}=w_{i, j, k}-\overline{w_{i, j, k}}$, as it affects the flow-induced dynamic loads on downwind turbines.

The characteristics of the streamwise velocity and the total turbulent intensity are averaged over the last $50 \mathrm{~min}$ of the corresponding 1-h wind-turbine simulation. The temporal average is calculated online in the numerical model and updated at every timestep according to the method of Fröhlich (2006, Eq. 9.1). Further, in the $x-z$ plane, the index $j_{0}$ corresponds to the centre of the domain in the $y$-direction, whereas in the $x$-y plane, $k_{h}$ corresponds to the hub height $z_{h}$.

\section{Idealized ABL simulation}

\subsection{Evolution}

The temporal evolution of the prescribed sensible heat flux at the surface, the vertical time series of the simulated potential temperature $\Theta=\Theta_{e}+\Theta^{\prime}$ and resolved TKE (Eq. 4) are shown in Fig. 1. The evolution of the potential temperature corresponds to the sensible heat flux with warming of the surface during the day and cooling at night. For negative surface flux values in $t \in[0 h, 5 h]$, the ABL in Fig. 1b consists of an SBL capped by the neutrallystratified residual layer. The increase of the surface fluxes at $t=5 \mathrm{~h}$ from their minimum level initiates the onset of the MBL, which results in a warming of the ABL surface layer in Fig. 1b. Convective thermals arise and the turbulent eddies increase in size and strength and start to form the CBL, which continues to grow throughout the morning eroding the stable layer from below 

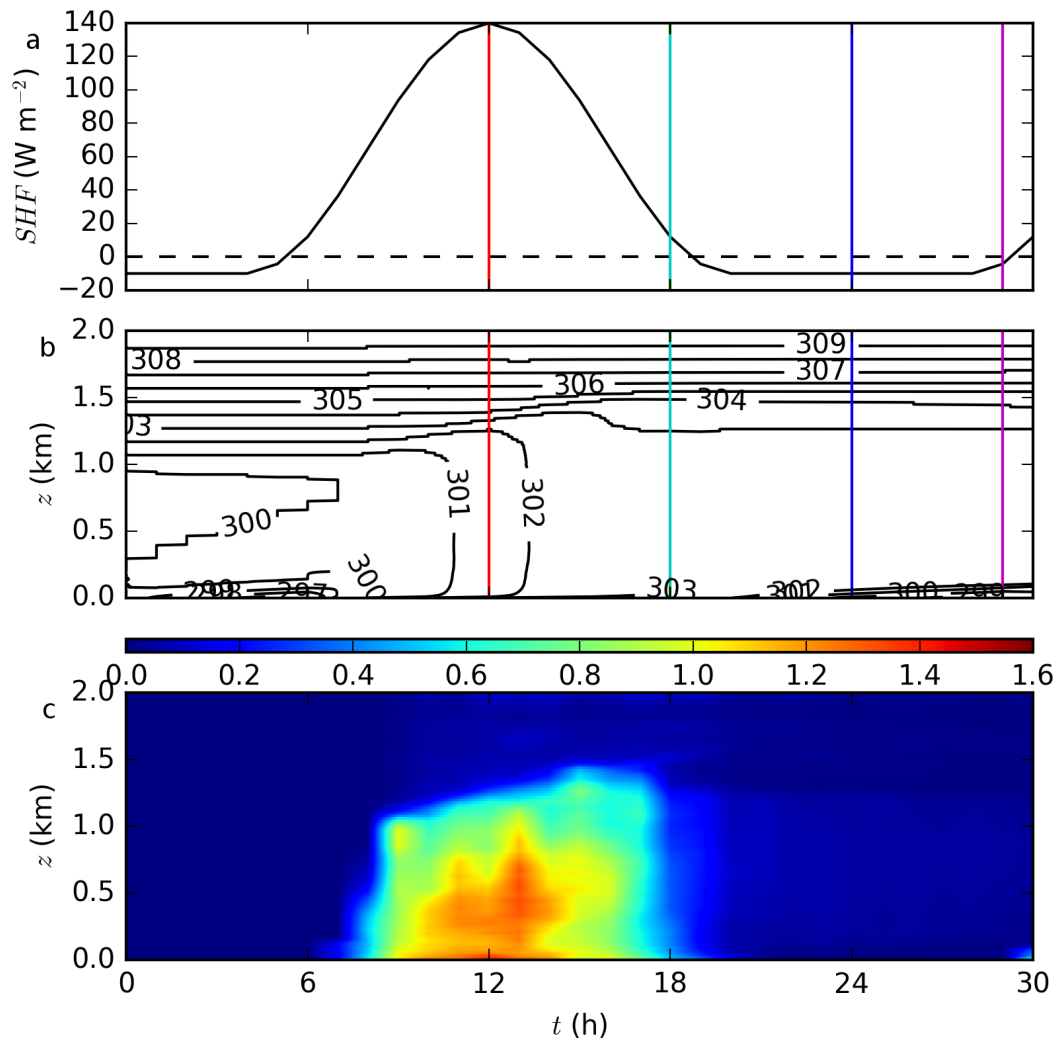

Fig. 1 Temporal evolution of the sensible surface heat flux in $\mathrm{W} \mathrm{m}^{-2}$ in (a), vertical time series of the horizontal average of the potential temperature $\Theta$ in $\mathrm{K}$ in (b), and of the horizontal average of the resolved TKE $\bar{e}$ in $\mathrm{m}^{2} \mathrm{~s}^{-2}$ in (c). The solid red (cyan, blue, magenta) line corresponds to the times when the background and initial fields are extracted from the idealized ABL simulation for the CBL (EBL, SBL, MBL) wind-turbine simulation.

and incorporating the residual layer. The subsequent decrease of the surface fluxes approaching their minimum level represents the EBL. In the EBL, the decaying CBL merges into the SBL. Further, the height of the ABL during the diurnal cycle simulation corresponds to the stronger stratification in Fig. 1b. The magnitude and the vertical extent of the resolved TKE in Fig. 1c shows a maximum during the day and a minimum during the night, in response to the simulated turbulence in the ABL. The maximum TKE has a delayed response to the maximum surface heat flux in Fig. 1a of approximately $2 \mathrm{~h}$. The overall characteristics of this temporal ABL evolution agree with previous studies of Stull (1988), Kumar et al. (2006), Basu et al. (2008), and Abkar et al. (2016). 

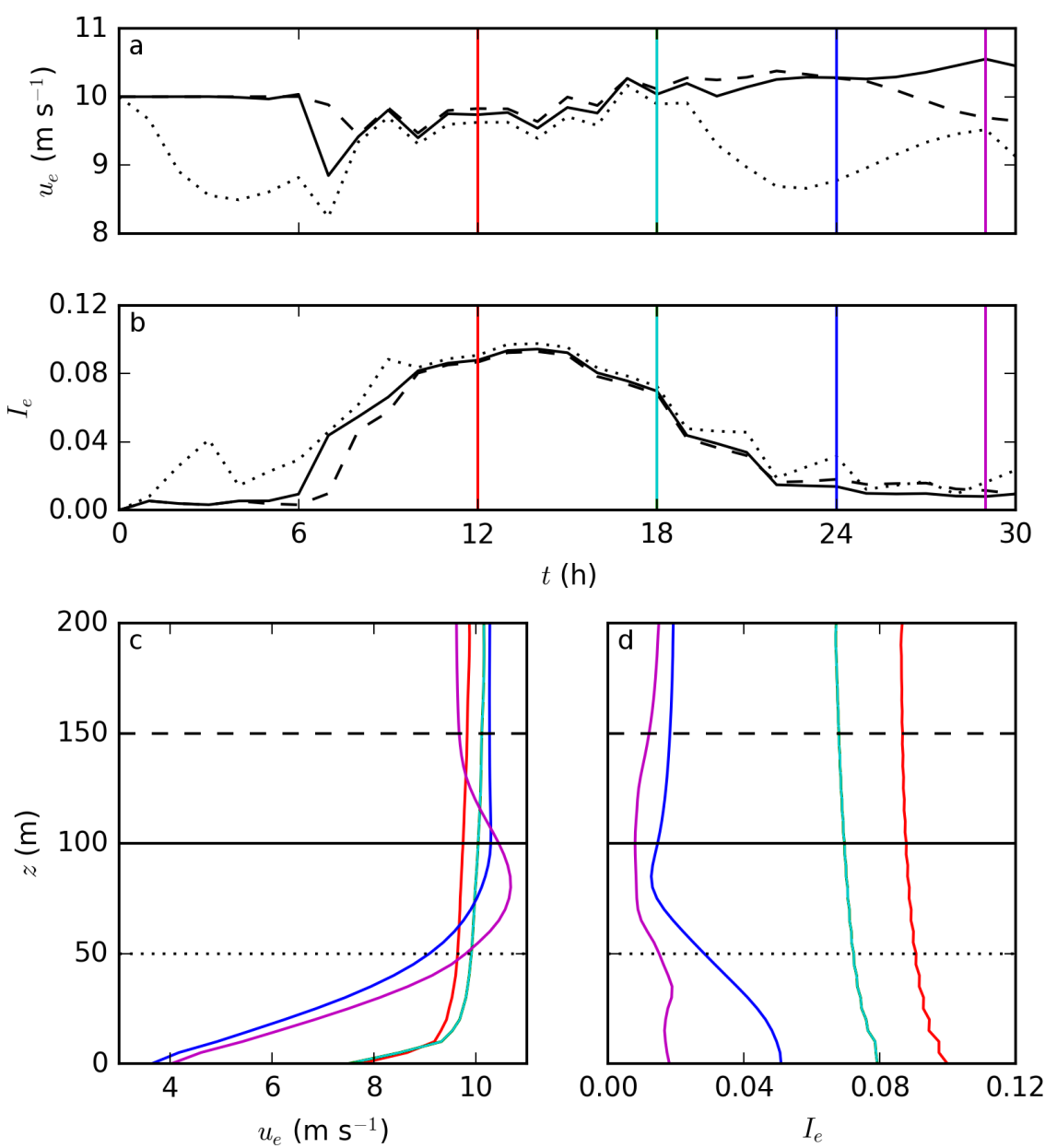

Fig. 2 Temporal evolution of the horizontal average of $u$ and $I$ of the idealized ABL simulation as $u_{e}$ and $I_{e}$ at hub height (100 m; black solid line), top tip (150 m; black dashed line) and bottom tip (50 m; black dotted line) of a wind turbine with $D=100 \mathrm{~m}$ and $z_{h}=100 \mathrm{~m}$ in (a) and (b). Vertical profiles of $u_{e}$ and $I_{e}$ are shown in (c) and (d). Colour coding of the vertical profiles follows the different regimes of the ABL, as shown in Fig. 1a and b.

\subsection{Atmospheric variables relevant to wind-energy research}

Wind speed, wind shear, and the level of atmospheric turbulence are the most important atmospheric variables in wind energy research (Naughton et al., 2011; Emeis, 2013, 2014; Abkar and Porté-Agel, 2014; Abkar et al., 2016), with a major impact on the structure of the flow field behind a wind turbine, the power loss, and the flow-induced dynamic loads on downwind turbines. The temporal evolution of the horizontal average of the streamwise velocity $u$ and the total turbulent intensity $I$ of the idealized ABL simulation are 
presented in Fig. 2a and $\mathrm{b}$ as $u_{e}$ and $I_{e}$ at hub height and at the height of the top tip and bottom tip of a wind turbine with $D=100 \mathrm{~m}$ and $z_{h}=100 \mathrm{~m}$. The corresponding vertical profiles of $u_{e}$ and $I_{e}$ are shown in Fig. $2 c$ and $d$.

The streamwise wind speed $u_{e}$ at a certain height in Fig. 2a is marginally impacted by the prescribed forcing during daytime conditions. All heights have nearly the same $u_{e}$-values due to the presence of the CBL. The $u_{e}$ variation between top tip height, hub height, and bottom tip height increases during the night. This difference between the day and nighttime behaviour results from the vertical wind shear, as shown in Fig. 2c. Specifically, in the CBL and EBL the vertical wind shear is rather small, whereas in the SBL and MBL it is pronounced. A supergeostrophic situation prevails during the MBL near hub height corresponding to an LLJ with a change in wind shear from a positive value below to a negative value above the LLJ.

Similar wind characteristics are found in Magnusson and Smedman (1994), Beare et al. (2006, Fig. 3), Kumar et al. (2006, Fig. 5), Basu et al. (2008, Fig. 3), Beare (2008, Fig. 2b), Bhaganagar and Debnath (2014, Fig. 1), Abkar and Porté-Agel (2014, Fig. 2a), Vollmer et al. (2016, Fig. 3a), and Abkar et al. (2016, Fig. 5a), amongst others. Furthermore an LLJ also exists in the SBL simulation of Aitken et al. (2014, Fig. 4), Bhaganagar and Debnath (2014, Fig. 1a), and Bhaganagar and Debnath (2015, Fig. 1), as well as in the diurnal cycle simulation of Abkar et al. (2016, Fig. 15a). In our simulation, the LLJ is not yet prevalent in the SBL, only a positive wind shear exists between the bottom tip and hub height. Generally, the onset time as well as the height of the LLJ depend on the amount of infrared irradiation at night and on the atmospheric situation of the previous day (Bhaganagar and Debnath, 2014, 2015).

The diurnal cycle has a large impact on the total turbulent intensity in Fig. $2 \mathrm{~b}$ with a maximum during the day and a minimum during the night, because the negative buoyancy damps the turbulence at night (Fig. 1c). The stratification results in much larger values of $I_{e}$ for the CBL and EBL and only small values for the SBL and MBL, as shown in Fig. $2 d$. A maximum in the streamwise turbulent intensity occurs below the LLJ (not shown here).

The diurnal behaviour, the order of magnitude, and the shape of the vertical profiles of total turbulent intensity in Fig. $2 \mathrm{~b}$ and d agree with investigations of Beare (2008, Fig. 4), Blay-Carreras et al. (2014, Fig. 7), Bhaganagar and Debnath (2014, Fig. 1), Abkar and Porté-Agel (2014, Fig. 2a,e-f), Vollmer et al. (2016, Fig. 3a), and Abkar et al. (2016, Fig. 3f, Fig. 5c, Fig. 15a), amongst others.

The larger total turbulent intensity in the CBL in comparison to the SBL is supposed to result in enhanced entrainment of ambient air into the wake region and, therefore, in a more rapid flow recovery in the wake. The similar structures of $u_{e}$ and $I_{e}$ in the CBL and EBL as well as in the SBL and MBL reveal a strong influence of the convective or stable stratification on the subsequent transitions. Similar transition behaviours are documented in Abkar et al. (2016). Therefore, the flow field in the wake of the wind turbine is sup- 
posed to be rather similar in the CBL and EBL and in the SBL and MBL. These assumptions are investigated in the following sections.

\section{Wind-turbine simulations}

The flow fields from the idealized ABL simulation are used as background, initial, and inflow conditions in the following wind-turbine simulations to investigate the wake structure for different diurnal cycle regimes with the coupling method described in Sect. 2.

\subsection{Wake structure}

The streamwise velocity for all four cases (CBL, EBL, SBL, MBL) is displayed in the $x-z$ plane in Fig. 3 and in the $x-y$ plane in Fig. 4 . The upstream region differs for the CBL and the EBL in comparison to the SBL and the MBL. This is caused by the difference in the upstream $u_{e}$ profiles in Fig. $2 c$. The general spatial structure results in a flow deceleration in the wake of the wind turbine and a recovery of the flow further downstream of the wind turbine. The downstream position of the flow recovery depends on the state of the ABL evolution, particularly on $I_{e}$. It is closer to the wind-turbine rotor for the CBL and further away for the SBL.

More precisely, the maximum velocity deficit is $50 \%$ in the CBL and $70 \%$ in the SBL. The flow in the wake also recovers more rapidly in the CBL in comparison to the SBL. The enhanced entrainment in the CBL results from high vertical and lateral momentum fluxes in Fig. 5. The high momentum fluxes are related to the increase of TKE, as shown in Fig. 1c, and the highest values of $I_{e}$ during the diurnal cycle, as shown in Fig. $2 \mathrm{~b}$ and d. The different entrainment rate results in a longer streamwise wake extension in the SBL in comparison to the CBL. These wake characteristics confirm the assumption of the more rapid flow recovery in the wake for decreasing stability and agree with previous investigations by Abkar and Porté-Agel (2014), Mirocha et al. (2015), Vollmer et al. (2016), and Abkar et al. (2016).

The recovery of the flow in the wake and the velocity deficit of the EBL (MBL) are comparable to the CBL (SBL) with a slightly longer wake region and larger velocity deficit values of $60 \%$ for the EBL ( $80 \%$ for the MBL). The vertical and lateral momentum fluxes of the EBL (MBL) are also comparable to the CBL (SBL), with slightly smaller values for increasing stability. The wake pattern verifies the assumption of the influence of the flow regime prior to the transitions on the wake during the transition phases.

The positive (negative) vertical and lateral momentum fluxes of $\overline{u^{\prime} w^{\prime}}$ and $\overline{u^{\prime} v^{\prime}}$ for the CBL and the SBL in Fig. 5 correspond to negative (positive) vertical and lateral gradients of the streamwise velocity in the wake (Figs. 3a and c, 4a and c). The large lateral momentum flux $\overline{u^{\prime} v^{\prime}}$ in the CBL can be attributed to a higher level of turbulence during day (Fig. 2b and d) and 

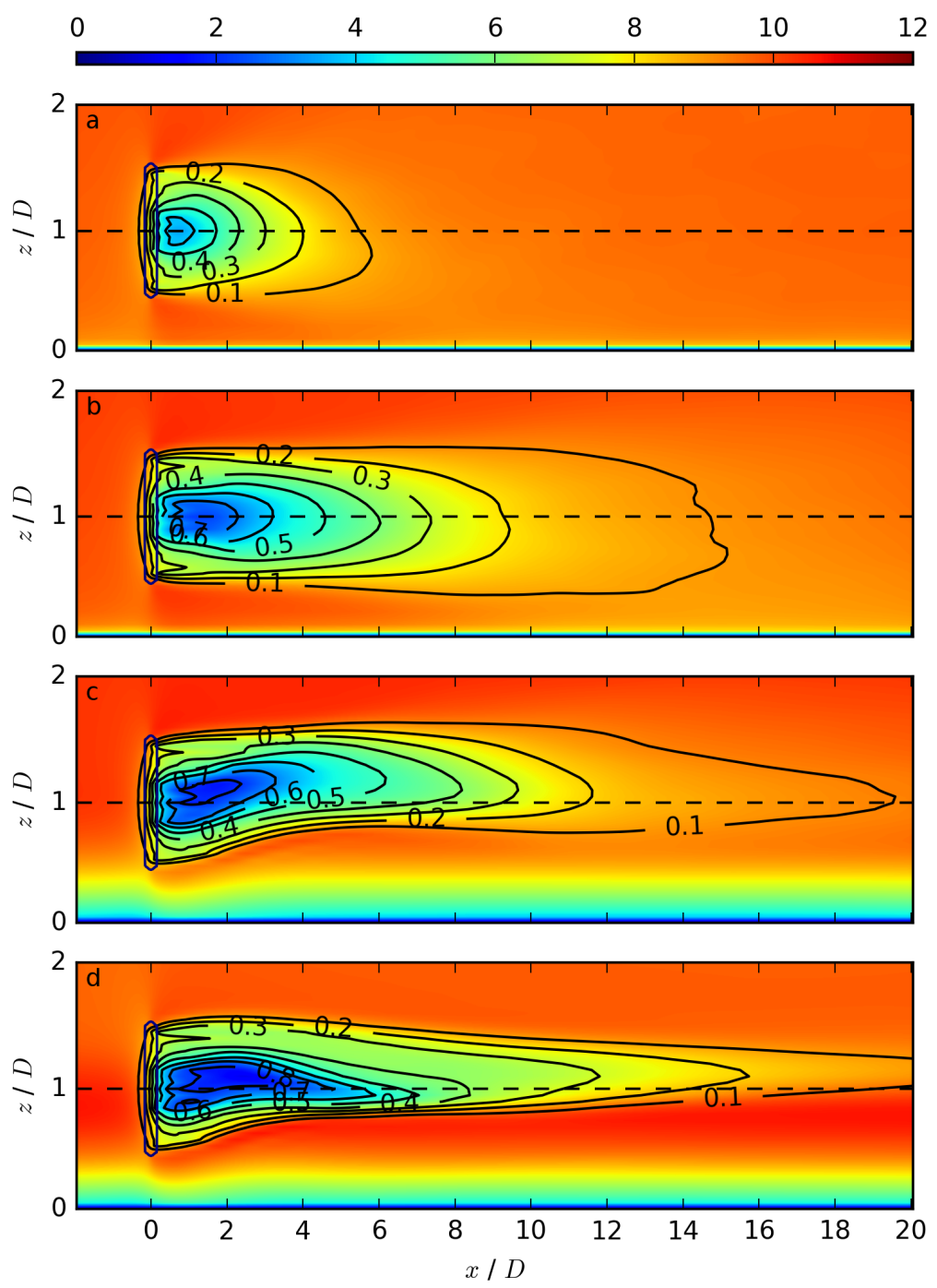

Fig. 3 Coloured contours of the streamwise velocity $\overline{u_{i, j_{0}, k}}$ in $\mathrm{m} \mathrm{s}^{-1}$ at a spanwise position of $j_{0}$, corresponding to the center of the rotor, averaged over the last $50 \mathrm{~min}$, for CBL in (a), EBL in (b), SBL in (c), and MBL in (d). The black contours represent the velocity deficit $V D_{i, j_{0}, k}$ at the same spanwise location. 

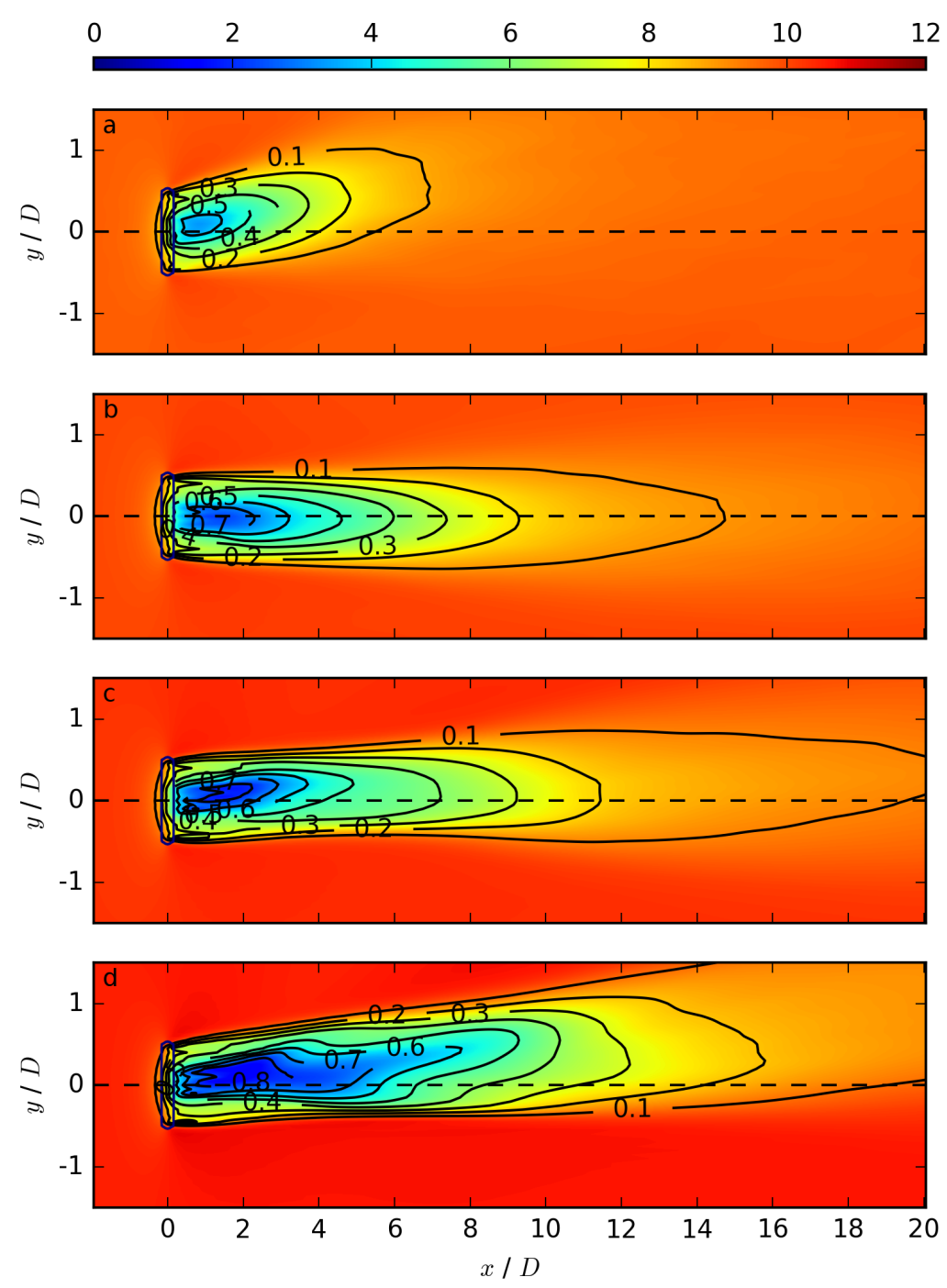

Fig. 4 Coloured contours of the streamwise velocity $\overline{u_{i, j, k_{h}}}$ in $\mathrm{m} \mathrm{s}^{-1}$ at hub height $z_{h}$, averaged over the last $50 \mathrm{~min}$, for CBL in (a), EBL in (b), SBL in (c), and MBL in (d). The black contours represent the velocity deficit $V D_{i, j, k_{h}}$ at the same vertical location. 

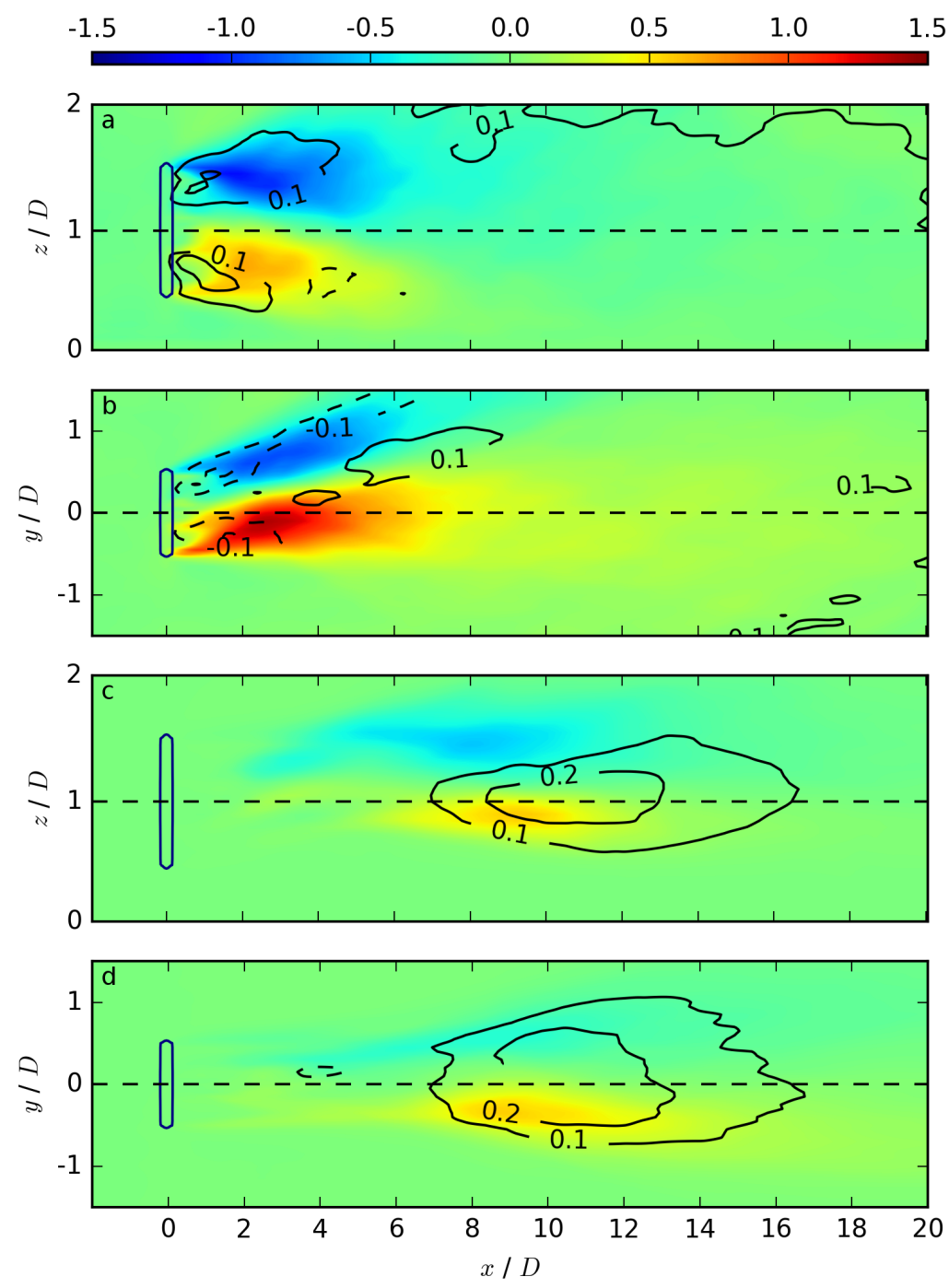

Fig. 5 Coloured contours of the vertical momentum flux $\overline{u^{\prime} w^{\prime}}$ in the $x-z$ plane at a spanwise position of $j_{0}$ corresponding to the center of the rotor for the CBL in (a) and for the SBL in (c). The same for the lateral momentum flux $\overline{u^{\prime} v^{\prime}}$ in the $x$-y plane at hub height $z_{h}$ for the CBL in (b) and for the SBL in (d). The black contours in all panels represent $\overline{v^{\prime} w^{\prime}}$. 

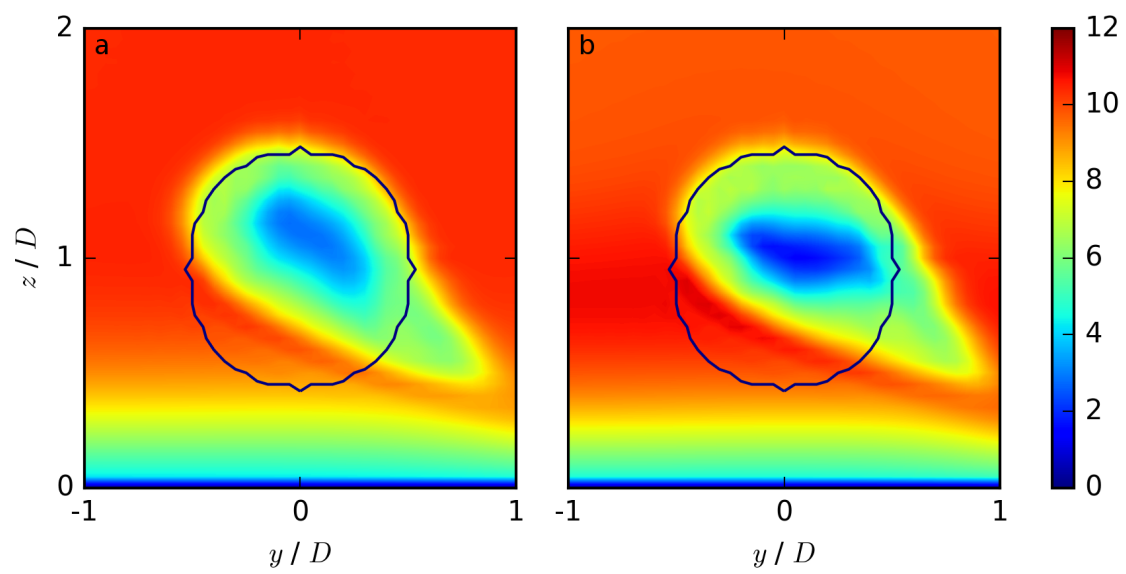

Fig. 6 Coloured contours of the streamwise velocity $\overline{u_{i=3 D, j, k}}$ in $\mathrm{m} \mathrm{s}^{-1}$ at a downward position of $3 \mathrm{D}$, averaged over the last $50 \mathrm{~min}$, for the SBL in (a) and the MBL in (b). Here, $y / D \in[0,1]$ corresponds to a northwards direction (wind direction angle $>270^{\circ}$ and wake deflection angle $<90^{\circ}$ ) and $y / D \in[-1,0]$ to a southwards direction (wind direction angle $<270^{\circ}$ and wake deflection angle $>90^{\circ}$ ). The black lines represent the rotor area.

the deflection of both maxima of $\overline{u^{\prime} v^{\prime}}$ towards the north can be attributed to the wake deflection in Fig. 4a. The positive momentum fluxes of $\overline{v^{\prime} w^{\prime}}$ in the CBL (Fig. 5a) are in agreement with a negative vertical gradient of the lateral velocity, whereas the negative momentum fluxes of $\overline{v^{\prime} w^{\prime}}$ (Fig. 5b) correspond to a positive vertical gradient of the lateral velocity. The maxima and minima of $\overline{u^{\prime} w^{\prime}}, \overline{u^{\prime} v^{\prime}}$, and $\overline{v^{\prime} w^{\prime}}$ are located in the near-wake region in the CBL, whereas they are in the far-wake region in the SBL. This difference is caused by the enhanced turbulent mixing in the near-wake region during day. At night, the near-wake region is dominated by advection processes and a deflection of the wake resulting from the Coriolis effect, and turbulent diffusion is gradually amplified in the far-wake region.

The wake structure, as shown in Fig. 3, is symmetric with respect to the centreline in the CBL and EBL, whereas it is asymmetric in the SBL and MBL. The asymmetric wake structure is presented in Fig. 6, where high $u$-values occur in the lower rotor part for $z<z_{h}$. This characteristic wake structure of the SBL and MBL results from the deflection of the wake towards the north $(y / D \in[0,1])$ and will be explained in the following section.

\subsection{Wake deflection}

Different horizontal deflections of the wake from an eastward propagating wake (no wake deflection $\equiv$ wake deflection angle of $90^{\circ}$ ) occur for the different regimes (Fig. 4). The wake deflections at hub height averaged over the near and far-wake region are $6^{\circ}$ to the north in the CBL (wake deflection angle $=84^{\circ}$ ), 
$0^{\circ}$ in the EBL (wake deflection angle $=90^{\circ}$ ), and $1^{\circ}$ to the north in the SBL and MBL (wake deflection angle $=89^{\circ}$ ). To investigate the height dependence of the wake deflection, the wind directions during the diurnal cycle at the height of the bottom tip, hub, and top tip are shown in Fig. 7c. Additionally, the wake deflections at these three heights (bt, hub, tt) are plotted as averages over the whole wake for the CBL, EBL, SBL, and MBL. Vertical profiles of the horizontal average of the wind direction for the four regimes are shown in Fig. 7a and the corresponding wind hodographs in Fig. 7b. The upstream wind conditions at bottom tip, hub, and top tip height correspond to the markers in Fig. 7b.

The upstream wind direction is nearly constant in the CBL and EBL, corresponding to nearly uniform values of $u_{e}$ and $v_{e}$ in the hodograph for the EBL. The hodograph for the CBL is comparable to the EBL and is not shown here. For the SBL and MBL, the upstream wind direction has a large vertical gradient between the bottom tip and top tip height and, therefore, a significant veering in the hodograph, which is especially pronounced in the lower rotor part. The wake deflections (markers in Fig. 7c) in the CBL and EBL are nearly constant across the height of the rotor area. They change with height in the SBL and MBL from from a northwards wake deflection (wake deflection angle $75^{\circ}$ ) at the bottom tip height to no wake deflection (wake deflection angle $90^{\circ}$ ) at the top tip height. This corresponds to the deformed wake towards the north in the lower rotor part in the $y-z$ plane for the SBL in Fig. 6a and for the MBL in Fig. 6b. Similar wake behaviour as in the SBL and MBL was found in the stable regime simulated by Lu and Porté-Agel (2011) and Vollmer et al. (2016), and in the low-stratified regime simulated by Bhaganagar and Debnath (2014).

The wake deflections in Fig. 7c correspond largely to the upstream wind directions for all ABL regimes and at all heights. The small deviations in the CBL and EBL decrease if only the averaged wind direction of the part of the precursor simulation which directly interacts with the wind turbine (20 grid points instead of 512) is considered. In this case, the meridional component in the CBL (EBL) is slightly stronger (weaker) than the horizontal average over the complete domain. The modified wind direction results in a larger (smaller) deviation from a westward wind than in the case for the whole domain, and therefore the wake deflection direction of the CBL (EBL) perfectly reflects the wind deflection.

\subsection{Streamwise velocity ratio and total turbulent intensity}

Figure 8 compares the dependencies of the streamwise velocity ratio and the total turbulent intensity through the centre of the rotor with measurements and numerical studies as listed in Table 1 . The velocity ratio values of the CBL in Fig. 8a are in agreement with the CBL results from Mirocha et al. (2014) for $x \geq 3 \mathrm{D}$. We compare the EBL results with neutral boundary layer (NBL) results, as no other published EBL wind-turbine simulations exist. For 


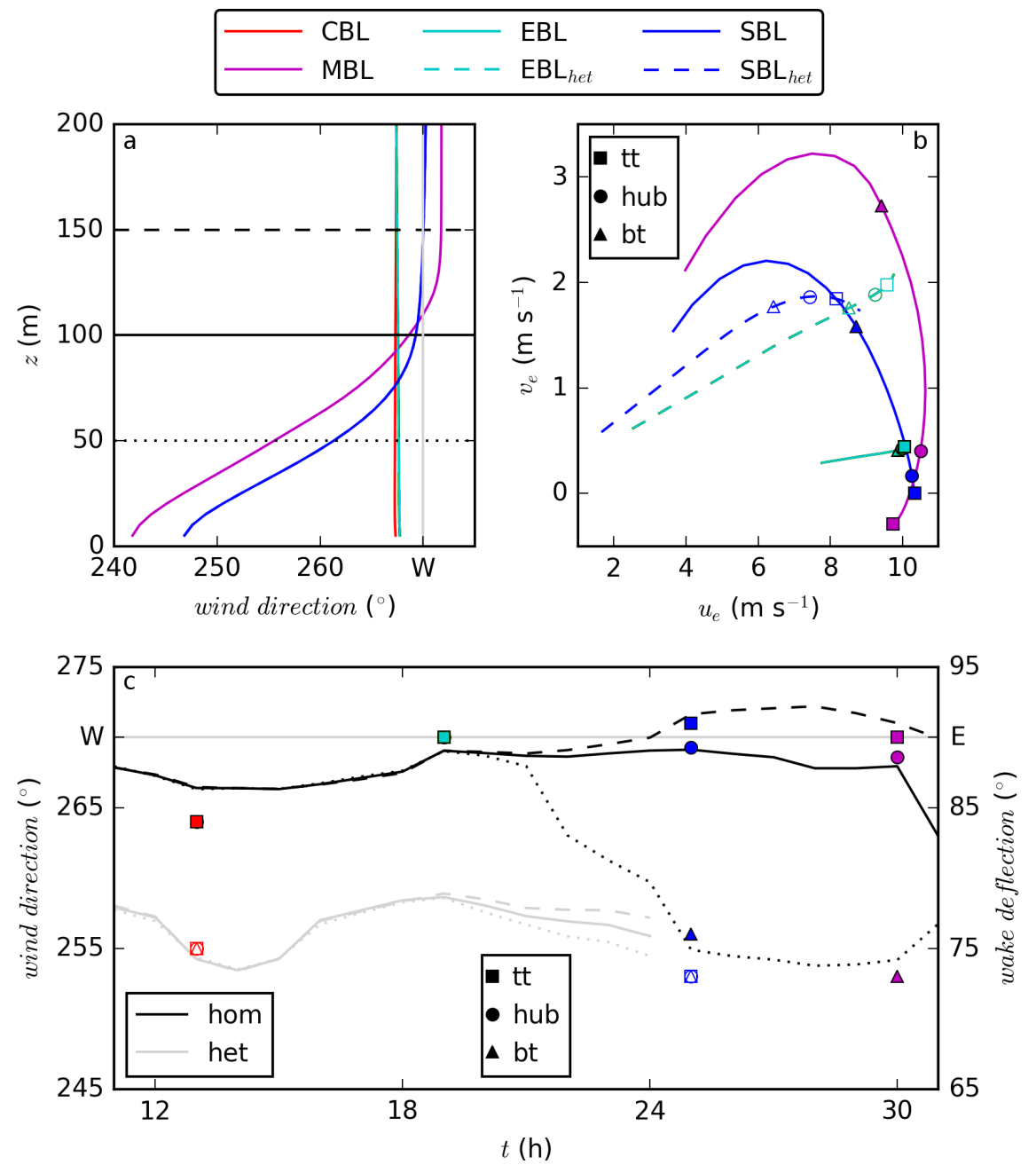

Fig. 7 Vertical profiles of the wind direction of the idealized ABL precursor simulation over homogeneous surface are shown in (a). The solid vertical gray line in (a) corresponds to a wind from the west. Wind hodographs, based on the mean zonal and meridional wind velocities $u_{e}$ and $v_{e}$ are shown in (b) for the EBL, EBL $\mathrm{EL}_{h e t}, \mathrm{SBL}, \mathrm{SBL}_{h e t}$, and MBL. Time evolution of the wind direction for the idealized ABL over a homogeneous (black) and heterogeneous (gray) surface is shown in (c). The markers correspond to the wind direction (in (b)) and wake deflection (in (c)) at the heights of the bottom tip (bt), hub (hub), and top tip (tt). The filled markers represent the homogeneous case, whereas the empty markers represent the heterogeneous case. The black lines in (a) and (c) correspond to a height of $50 \mathrm{~m}$ (dotted line), $100 \mathrm{~m}$ (solid line), and $150 \mathrm{~m}$ (dashed line). 

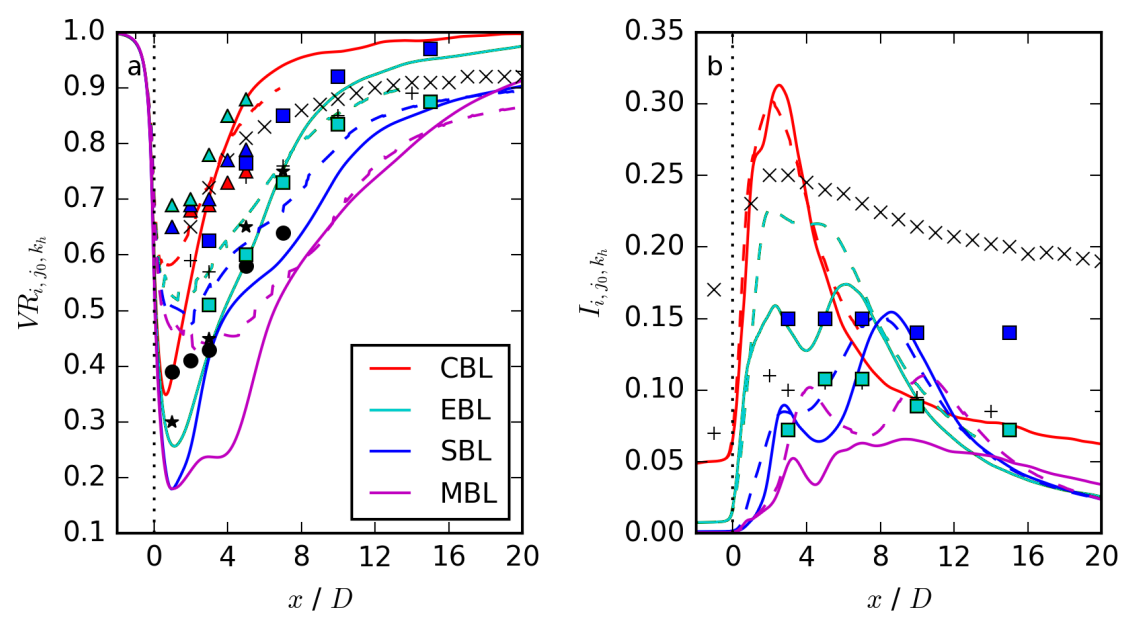

Fig. 8 Dependency of the streamwise velocity ratio $V R_{i, j_{0}, k_{h}}$ in (a) and the total turbulent intensity $I_{i, j_{0}, k_{h}}$ in (b) for the wind-turbine simulations CBL, EBL, SBL, and MBL through the centre of the rotor in the spanwise $\left(j_{0}\right)$ and vertical $\left(k_{h}\right)$ direction (solid lines). The dashed lines correspond to the average of the streamwise velocity ratio and the total turbulent intensity in the wake at hub height $z_{h}$ for $V R>0.1$. The markers correspond to various studies as listed in Table 1 . No error bars are shown, as they are $<0.1 \%$ of both quantities.

the EBL, our LES results are in agreement with the NBL simulations of $\mathrm{Wu}$ and Porté-Agel $(2011,2012)$ for the smaller roughness length value. For the SBL, our simulation results are in good agreement with SBL measurements and numerical simulation results from Aitken et al. (2014). For the MBL, the results of the numerical model EULAG are comparable to the SBL with smaller values resulting from the more stable situation (Fig. 2d).

The total turbulent intensity profiles in Fig. $8 \mathrm{~b}$ through the rotor centre in the EBL, SBL, and MBL are comparable to the range of other NBL LES results with different values of the roughness length in Wu and Porté-Agel (2011, 2012). The values are larger in the near-wake region in the CBL in comparison to the EBL, SBL, and MBL, resulting from the domination of the streamwise turbulent intensity component over the spanwise and vertical componenets (not shown here). Compared to the Reynolds-averaged Navier-Stokes (RANS) simulation of Gomes et al. (2014), the turbulent intensity values are smaller in our LES. The velocity ratio in Fig. 8a, however, is comparable for the LES and RANS simulations, which indicates a strong dependence of the total turbulent intensity in the far-wake region on the numerical model (Englberger and Dörnbrack, 2017).

To test whether the velocity ratio and total turbulent intensity values at $i, j_{0}$, and $k_{h}$ are representative for the whole wake, especially regarding the wake deflections in Fig. 4, an average of $V R$ and $I$ (dashed lines) is taken at $k_{h}$ for all grid points with a velocity deficit $>0.1$ in lateral direction, denoted by 
Table 1 List of all used markers for the velocity ratio and the total turbulent intensity of a wind turbine, resulting from various studies.

\begin{tabular}{|c|c|c|}
\hline Symbol & Origin & Reference \\
\hline+ & NBL LES & Wu and Porté-Agel (2011, Fig. 4) \\
\hline+ & NBL LES & Wu and Porté-Agel (2011, Fig. 4) \\
\hline$\times$ & RANS & Gomes et al. (2014, Fig. 1) \\
\hline$\bullet$ & lidar measurements & Aitken et al. (2014, Fig. 6) \\
\hline$\star$ & WRF-LES & Aitken et al. (2014, Fig. 6) \\
\hline$\Delta$ & CBL measurements & Mirocha et al. (2014, Fig. 8) \\
\hline $\mathbf{\Delta}$ & WRF-LES $\left(\mathrm{SHF}=20 \mathrm{~W} \mathrm{~m}^{-2}\right)$ & Mirocha et al. (2014, Fig. 8) \\
\hline$\triangle$ & WRF-LES $\left(\mathrm{SHF}=100 \mathrm{~W} \mathrm{~m}^{-2}\right)$ & Mirocha et al. (2014, Fig. 8) \\
\hline$\square$ & NBL LES $z_{0}=1 \times 10^{-5} \mathrm{~m}$ & Wu and Porté-Agel (2012, Fig. 5) \\
\hline$\square$ & NBL LES $z_{0}=1 \times 10^{-1} \mathrm{~m}$ & Wu and Porté-Agel (2012, Fig. 5) \\
\hline
\end{tabular}

$<V R_{i, j, k_{h}}>_{V R>0.1}$ and $\left\langle I_{i, j, k_{h}}>_{V R>0.1}\right.$. This lateral average corresponds to the area within the 0.1 contour in Fig. 4 and considers the wake deflections. For the calculation of the velocity deficit in Eq. $6,\left\langle\overline{u_{i_{1}, k_{h}}}\right\rangle_{j}$ is used in the denominator as a lateral average instead of a grid point value $\overline{u_{i_{1}, j, k_{h}}}$.

The averaged velocity ratio in Fig. 8a (dashed lines) is smaller due to including the complete wake with decreasing $V R$ values at the rotor edges. The individual relation between the different regimes is comparable to $V R_{i, j_{0}, k_{h}}$, with the maximum $V R$ in the CBL and the minimum in the MBL. A comparison to other studies is not possible, as the markers correspond to downstream values located at the centre of the rotor area.

The averaged total turbulent intensity values in Fig. 8b (dashed lines) are comparable to $I_{i, j_{0}, k_{h}}$. Especially in the CBL and SBL, the dashed and solid lines are nearly overlapping. Minor differences occur in the EBL and in the MBL. Further, the individual relation between the different regimes is still prevalent, with a maximum of the total turbulent intensity in the CBL and a minimum in the MBL.

The streamwise development of $V R_{i, j_{0}, k_{h}}$ and $I_{i, j_{0}, k_{h}}$ through the centre of the rotor are in agreement with the averaged values of $\left\langle V R_{i, j, k_{h}}>_{V R>0.1}\right.$ and $\left\langle I_{i, j, k_{h}}>_{V R>0.1}\right.$ and can therefore be considered as representative of the whole wake. For a larger deviation of the wind direction from a westward wind than in this study, the averaged values might be more significant.

\subsection{Temporal average}

To test whether the applied 50 min averaging period is sufficient to generate statistically converged results, the turbulent intensities for the CBL, the EBL, the SBL, and the MBL are shown in Fig. 9 for time averages of $10 \mathrm{~min}$, $30 \mathrm{~min}$, and $50 \mathrm{~min}$, respectively. Here, $\left\langle I_{i, j, k_{h}}\right\rangle_{V R>0.1}$ is averaged over all grid points at hub height with $V R>0.1$.

The turbulent intensities for the SBL and the MBL are independent of the averaging time and follow the same spatial profiles. The difference of $<$ 

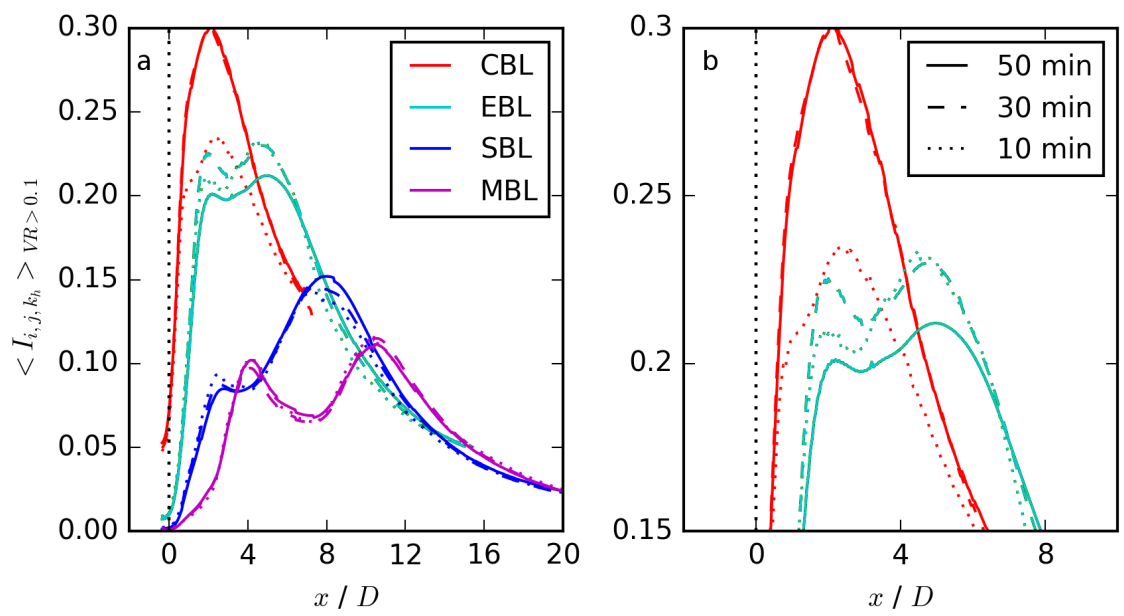

Fig. 9 Total turbulent intensity $<I_{i, j, k_{h}}>_{V R>0.1}$ as function of $x / D$ averaged over all grid points at hub height $z_{h}$ with $V R>0.1$ for the CBL, EBL, SBL, and MBL wind-turbine simulations in (a). $\left\langle I_{i, j, k_{h}}>_{V R>0.1}\right.$ is plotted for time average periods of $10 \mathrm{~min}, 30 \mathrm{~min}$, and $50 \mathrm{~min}$, respectively. The upper section of the difference time averages of $\left\langle I_{i, j, k_{h}}\right\rangle_{V R}>0.1$ for the CBL and the EBL is shown in (b).

$I_{i, j, k_{h}}>_{V R>0.1}$ for the CBL between the 10-min and the 30-min averages is large. However, between the 30-min and 50-min averages, there is no significant difference. An averaging time of 20 min already corresponds to the 30-min profile (not shown), which means the simulation results are statistically stable after about 20-min averaging time. The difference after $10 \mathrm{~min}$ in comparison to the longer temporal averages results from insufficient time for the wake to reach an equilibrium state with statistical convergence of the results.

In the EBL, the 10-min and 30-min averages are rather similar, whereas the total turbulent intensity profiles deviate significantly for the 50-min values. The 40-min values correspond to the 50-min values (not shown). The difference between an averaging time of $30 \mathrm{~min}$ and $40 \mathrm{~min}$ can be related to the buoyancy contribution to turbulence, which is controlled by the temporal evolution of the surface heat flux as shown in Fig. 1a. The decreasing surface flux is still positive after $10 \mathrm{~min}(17 \mathrm{~h}$ and $10 \mathrm{~min})$ and $30 \mathrm{~min}$ (17 h and $30 \mathrm{~min})$, crossing zero after $40 \mathrm{~min}(17 \mathrm{~h}$ and $40 \mathrm{~min})$, and is negative after $50 \mathrm{~min}$ averaging time (17 $\mathrm{h}$ and $50 \mathrm{~min})$.

In contrast to the EBL, no changes in the turbulent intensities occur in the MBL for longer averaging periods. Here, the surface fluxes become positive after about $10 \mathrm{~min}$. This different behaviour can be explained by the longer time scales in the MBL related to the growth of turbulent eddies by forming a fully convective layer. In contrast, the surface cooling leads to a fast response of the lowest few hundred metres of the atmosphere to the absence of thermals in the EBL. 


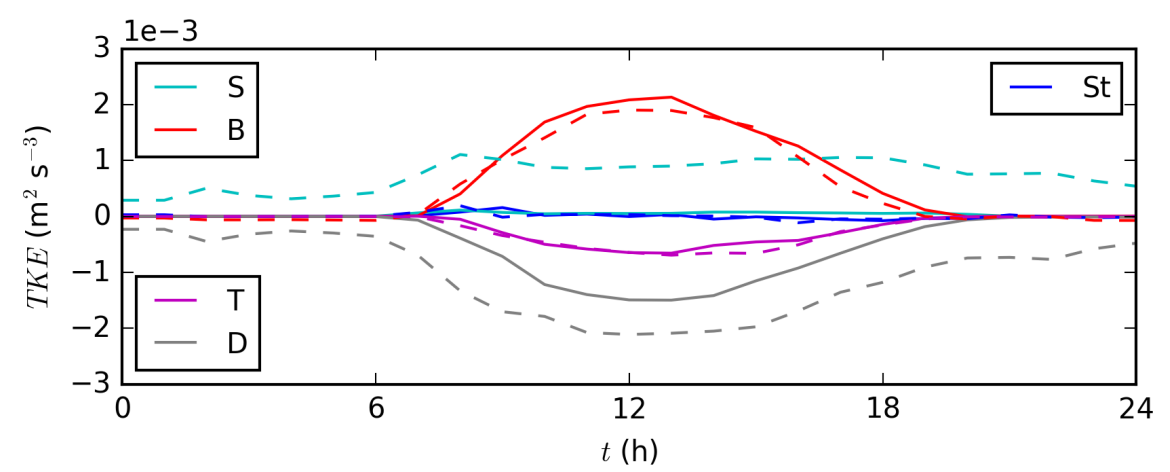

Fig. 10 Temporal evolution of the TKE budget terms from Eq. 5 for the idealized ABL over a homogeneous surface as solid lines and for the idealized ABL over a heterogeneous surface as dashed lines. $\mathrm{S}$ corresponds to shear, B to buoyancy production, $\mathrm{T}$ to turbulent transport, D to dissipation, and St to storage.

Different time periods were chosen in previous studies to average the respective numerical results. For the SBL, Bhaganagar and Debnath (2014) averaged over $100 \mathrm{~s}$, Mirocha et al. (2015) over $10 \mathrm{~min}$, Vollmer et al. (2016) over $20 \mathrm{~min}$, and Abkar et al. (2016) over $1 \mathrm{~h}$. According to our investigation in Fig. 9a, all of these averaging periods lead to the same result. Therefore, an averaging period of $10 \mathrm{~min}$ is sufficient and preferred, regarding the computational costs.

As other wind-turbine simulations of the EBL have not yet been published, we compare our applied averaging period to available simulations of the NBL. For example, Vollmer et al. (2016) averaged over $20 \mathrm{~min}$, similar to their SBL case. If the surface fluxes did not cross zero, this time period would also be appropriate for our simulation. However, as mentioned above, the situation is different for the EBL due to the surface cooling. Therefore, the applied time scale cannot be compared to the NBL simulation with zero surface heat flux.

For the CBL, the values used in the literature reveal a wide spread of averaging times. Mirocha et al. (2015) averaged over $10 \mathrm{~min}$, Abkar et al. (2016) and Vollmer et al. (2016) over $1 \mathrm{~h}$. Vollmer et al. (2016) motivated this long averaging period by positive and negative meridional winds, resulting in a local inflow wind direction, which differs from the wind direction averaged over the whole domain. In our simulation, the meridional wind component is always positive from $12 \mathrm{~h}$ to $13 \mathrm{~h}$ for the 20 grid points that have a direct influence on the wind-turbine wake. Therefore, a 20-min average is sufficient in our case to reach an equilibrium state with statistical convergence of the results. 


\section{Heterogeneous surface}

\subsection{Idealized atmospheric boundary-layer simulation}

The vertical time series of potential temperature and resolved TKE for the idealized diurnal cycle simulation over a heterogeneous surface (as described in Sect. 2.2) show essentially the same behaviour above the blending height as those from the idealized diurnal cycle simulation over a homogeneous surface shown in Fig. 1. The main difference occurs below the blending height, which is $>200 \mathrm{~m}$, due to the enhanced shear induced by the obstacles on the ground. Figure 10 reveals that the shear production term is significantly larger compared to the homogeneous run during the full diurnal cycle. Further, the shear production term has the same order of magnitude as the buoyancy budget term during the daytime.

The heterogeneous surface has an impact on wind speed, wind shear, and the level of atmospheric turbulence (Dörnbrack and Schumann, 1993; Belcher et al., 2003; Bou-Zeid et al., 2004; Millward-Hopkins et al., 2012; Kang et al., 2012; Kang and Lenschow, 2014; Calaf et al., 2014). Figure 11 displays vertical profiles of the horizontal averages of the zonal and meridional wind components in (a) and (b) as well as the wind direction in (c) and the total turbulent intensity in (d) after $12 \mathrm{~h}$ and $24 \mathrm{~h}$ of both idealized ABL simulations for the CBL and the SBL over homogeneous and heterogeneous terrain. In the following, the EBL and MBL over the heterogeneous surface are not discussed. The results for the MBL are similar to those of the SBL over the homogeneous surface due to the dominant shear effect. The results for the EBL over the homogeneous surface are already influenced by the averaging, which makes an investigation of the general impact of the surface condition rather difficult.

For daytime and nighttime conditions, the horizontally-averaged zonal winds above the heterogeneous surface are smaller than those for the homogeneous surface (Fig. 11a). As expected, they are smaller in $\mathrm{SBL}_{h e t}$ than in $\mathrm{CBL}_{h e t}$ at the rotor levels between $50 \mathrm{~m}$ and $150 \mathrm{~m}$ above ground level. In contrast, the homogeneous simulations produce approximately the same zonal wind speeds for the SBL and the CBL at these heights. Furthermore, the zonal velocity shear over the lower part of the rotor is less pronounced in $\mathrm{SBL}_{h e t}$ and has nearly the same values across the whole rotor. No significant zonal velocity shear is prevalent in both CBL and $\mathrm{CBL}_{h e t}$. The vertical profiles of the meridional velocity components for the homogeneous SBL and CBL cases differ as shown in Fig. 11b. In contrast, the heterogeneous results show nearly the same magnitude and shape of the $v_{e}$-profiles for $\mathrm{CBL}_{h e t}$ and $\mathrm{SBL}_{h e t}$. Their vertical structure is similar to the well-mixed profiles of a convective boundary layer with nearly vanishing vertical shear at the rotor levels. However, the meridional velocities are significantly higher in both heterogeneous runs in comparison to the homogeneous CBL.

The horizontal averages of the zonal and meridional velocity profiles of both heterogeneous cases result in nearly straight hodographs with minimal directional shear across the rotor levels as shown as dashed lines in Fig. 7b 

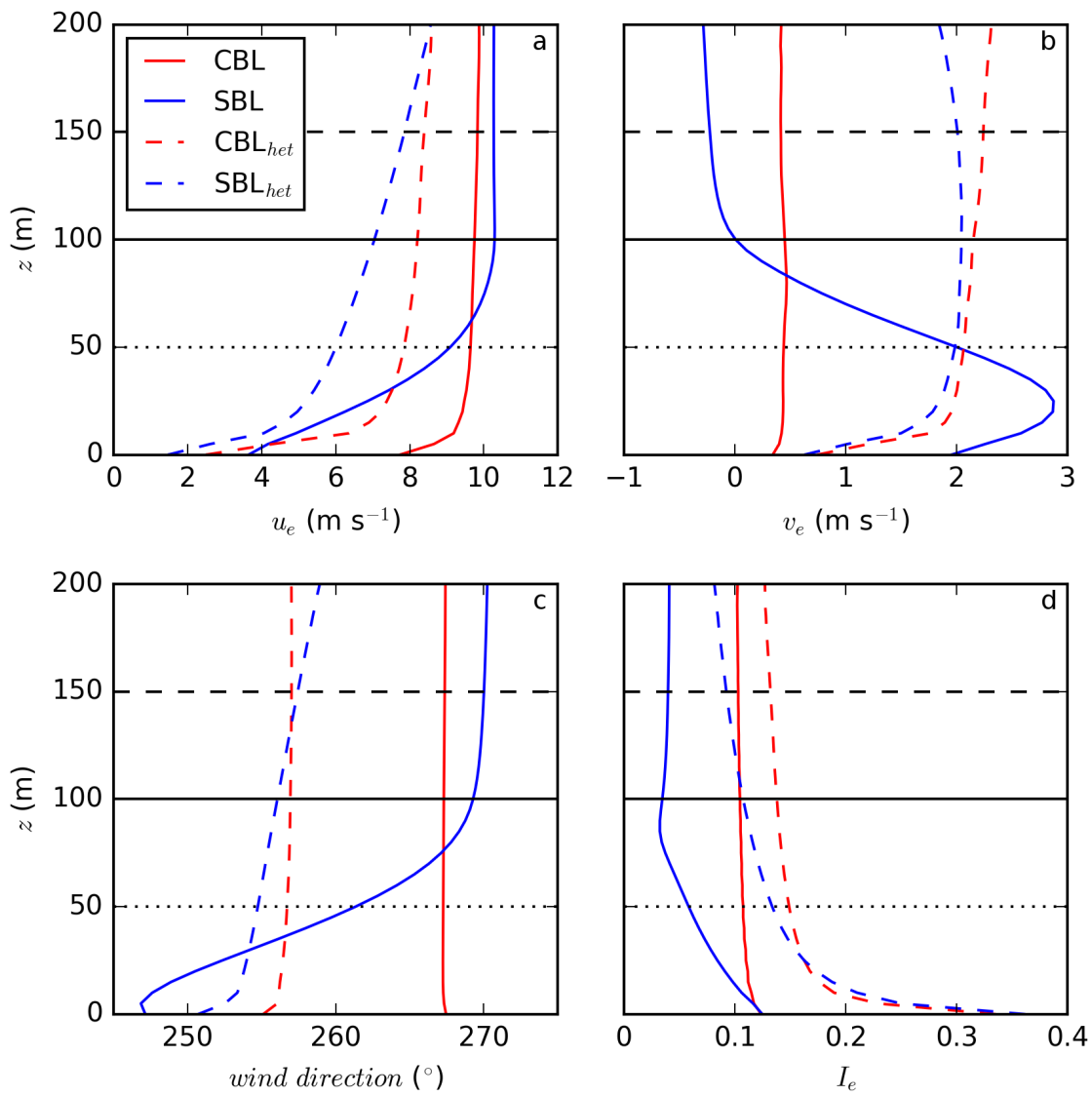

Fig. 11 Vertical profiles of $u_{e}, v_{e}$, the wind direction, and $I_{e}$ are shown as horizontal averages of $u, v$, and $I$ in (a), (b), (c), and (d). The solid red (blue) line corresponds to the $\mathrm{CBL}(\mathrm{SBL})$ and the dotted red (blue) line to $\mathrm{CBL}_{h e t}\left(\mathrm{SBL}_{h e t}\right)$.

$\left(\mathrm{CBL}_{h e t}\right.$ is rather similar to $\mathrm{EBL}_{h e t}$, which is plotted as a counterpart to the EBL, and is therefore not shown in the hodograph). The marginal change in the wind direction with height is also visible in Fig. 11c; wind direction differences of $15^{\circ}$ towards the south for $\mathrm{SBL}_{h e t}$ in comparison to SBL and of $12^{\circ}$ towards the south for $\mathrm{CBL}_{h e t}$ in comparison to CBL exist at hub height.

The enhanced shear produced by the flow over the obstacles results in a much larger total turbulent intensity $I_{e}$ in the lowest levels for $\mathrm{CBL}_{h e t}$ and $\mathrm{SBL}_{\text {het }}$ in comparison to CBL and SBL as shown in Fig. 11d. The magnitude of the horizontally-averaged total turbulent intensity is approximately the same for $\mathrm{CBL}_{\text {het }}$ and $\mathrm{SBL}_{\text {het }}$ up to a height of roughly $25 \mathrm{~m}$. At the height of the rotor, $I_{e}$ is larger for $\mathrm{CBL}_{h e t}$ in comparison to $\mathrm{SBL}_{h e t}$ and the values even exceed $I_{e}$ for the homogeneous CBL. Moreover, $I_{e}$ in $\mathrm{SBL}_{h e t}$ is approximately five times larger than in the homogeneous SBL. As for the 


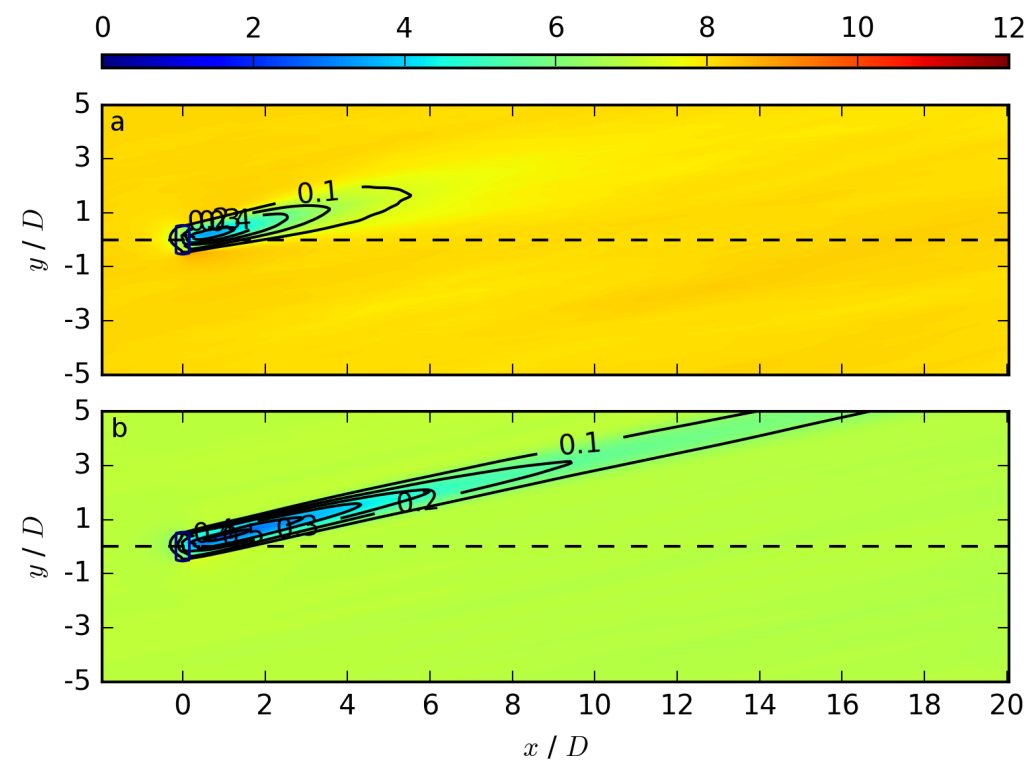

Fig. 12 Contours of the streamwise velocity $\overline{u_{i, j, k_{h}}}$ in $\mathrm{m} \mathrm{s}^{-1}$ at hub height $z_{h}$, averaged over the last $50 \mathrm{~min}$, for $\mathrm{CBL}_{h e t}$ in (a) and $\mathrm{SBL}_{h e t}$ in (b). The black contours represent the velocity deficit $V D_{i, j, k_{h}}$ at the same vertical location.

zonal wind component, the vertical gradient of $I_{e}$ is nearly constant across the rotor levels for $\mathrm{SBL}_{h e t}$ whereas the $I_{e}$-profile for the homogeneous SBL run shows pronounced shear across the lower part of the rotor. The differences of $I_{e}$ between $\mathrm{CBL}$ and $\mathrm{CBL}_{h e t}$ and likewise between $\mathrm{SBL}$ and $\mathrm{SBL}_{h e t}$ result from the intensified contribution of shear production over the heterogeneous surface (Fig. 10), whereas the differences between CBL and SBL and likewise between $\mathrm{CBL}_{h e t}$ and $\mathrm{SBL}_{h e t}$ are related to the buoyancy budget term with a maximum value during the day. The significantly different profiles of the mean quantities for the heterogeneous cases are caused by the mechanical production of TKE (Fig. 10). The enhanced turbulent mixing in the lower part of the ABL counteracts the formation of an Ekman spiral for the stably-stratified case (Fig. 7b). Moreover, the increased turbulence causes similar vertical profiles of the horizontal average of the zonal and meridional wind components, the wind direction, and the total turbulent intensity for $\mathrm{SBL}_{h e t}$ and $\mathrm{CBL}_{h e t}$.

\subsection{Wind-turbine simulations}

The ABL flow fields from the idealized simulation over the heterogeneous surface are used as background profiles and as initial and inflow conditions for the subsequent wind-turbine simulations. The aim is to investigate the wake structure during the day and night over the heterogeneous terrain and to compare the results to the corresponding homogeneous wind-turbine simulations. The 
impact on the wake is shown in the $x-y$ cross-sections in Fig. 12 for $\mathrm{CBL}_{h e t}$ in (a) and for $\mathrm{SBL}_{h e t}$ in (b). First of all, the upstream values of the streamwise velocity in the $\mathrm{CBL}_{h e t}$ and $\mathrm{SBL}_{h e t}$ runs are smaller in comparison to the results for the homogeneous CBL and SBL runs in Fig. 4a and c, as already indicated by Fig. 11a. Furthermore, as also indicated by Fig. 11a, they are smaller for $\mathrm{SBL}_{h e t}$ in comparison to $\mathrm{CBL}_{h e t}$.

The maximum velocity deficit is smaller for $\mathrm{CBL}_{\text {het }}$ (0.4 compared to 0.5 for the homogeneous case) and for $\mathrm{SBL}_{\text {het }}$ (0.5 compared to 0.7 for the homogeneous case). In accordance with the enhanced turbulence provided by the precursor simulation, the ambient flow recovers more rapidly in both heterogeneous cases whereby the $\mathrm{CBL}_{\text {het }}$ run shows a shorter downstream wake extension than the $\mathrm{SBL}_{h e t}$ run. Both wakes in Fig. 12 are deflected towards the north (wake deflection angle $<90^{\circ}$ ). As the ABL is well mixed at the rotor heights, even at night, the northward deflection occurs at all vertical levels. Similar to the homogeneous runs, the wake deflections coincide with the ambient wind direction averaged over the upstream section of the domain which directly interacts with the wind turbine.

This investigation reveals a profound impact of the surface conditions on the low-level wind and turbulence of the precursor ABL simulations and, therefore, on the resulting wake structures in the wind-turbine simulations. In particular, the wake during the night is completely different for heterogeneous surface conditions in comparison to the homogeneous case. As mentioned before, the difference results from the large increase of the shear production term of the TKE budget, which leads to enhanced vertical mixing and eliminates the Ekman spiral of the homogeneous SBL. In this work, we use an upstream region of $300 \mathrm{~m}$ for the heterogeneous wind-turbine simulations to make them comparable to the homogeneous ones. The impact of the surface condition from the precursor simulation can be less distinct if the upstream region between the obstacles and the wind turbine is increased, however, the impact should not become negligible.

\section{Conclusion}

The wake characteristics of a single wind turbine for different regimes occurring throughout a full diurnal cycle were studied by means of LES for flow over homogeneous and heterogeneous terrain. The flow field of an idealized ABL precursor simulation was used as synchronized atmospheric inflow conditions for the interface between the ABL and the wind-turbine simulations. The turbine-induced forces were parametrized with the blade element momentum method as rotating actuator discs. The numerical simulations using these two ingredients result in realistic wake structures, which are quantitatively comparable with previous observations and numerical simulation results throughout the full diurnal cycle.

The simulation results from an idealized diurnal cycle simulation of the ABL revealed a significant diurnal effect on wind shear and atmospheric tur- 
bulence in the lowest $200 \mathrm{~m}$ over the course of a day. In particular, the low-level vertical wind shear is strong in the SBL and MBL, whereas it is insignificant in the CBL and EBL. On the other hand, the total turbulent intensity is much larger in the CBL and EBL in comparison to the SBL and MBL. During the night an LLJ forms at the height of the wind-turbine rotor and is prevalent in the MBL. These various atmospheric conditions occurring in the course of a day are highly important for studying the interaction of the ABL flow with a wind turbine, considering that near-neutral stratification, which has often been applied in previous numerical wind-turbine studies, occurs for example only with a frequency of roughly $10 \%$ according to data from the SWiFT field experiment (Facility Representation and Preparedness; 730 days of measurement in the period from 2012 to 2014) (Kelley and Ennis, 2016).

In contrast to the idealized ABL simulations, the wind-turbine simulations are performed with open streamwise boundaries. These simulations are initialized with $3 \mathrm{D}$ fields from the LES of the ABL at four times typical for the CBL, the EBL, the SBL, and the MBL. Two-dimensional slices of the evolving velocity components and potential temperature pertubations from the idealized ABL simulations are used as synchronized inflow conditions at every timestep. The wakes resulting from the interaction of the time-dependent ABL flow and the wind turbine are strongly influenced by the respective regimes of the ABL evolution. Specifically, the wake recovers more rapidly under convective conditions during the day, compared to at night. This difference is related to the positive buoyancy flux during the day, which results in a higher total turbulent intensity of the incoming wind, increasing the vertical and lateral momentum fluxes and therefore the entrainment of higher momentum air into the wake. The wake characteristics representing the morning and the evening conditions provide the first insight in the wake structures during transitional periods, which show a strong influence of the flow regime prior to the transition.

Furthermore, the horizontal wake deflections vary with height in the SBL and MBL in response to the change of the upstream wind direction between the bottom tip and hub height of the rotor. In the CBL and EBL, the wake deflections are also determined by the incoming wind direction, which is, however, constant over the rotor area. Furthermore, a short temporal averaging period of about $10 \mathrm{~min}$ is sufficient for obtaining reliable statistical results for the wind-turbine simulations representing the SBL and the MBL. However, the averaging period for the EBL is strongly affected by the occurrence of thermals, and in the CBL by the temporal meridional wind fluctuations. These results allow adjustments of the domain size and the simulation time of a wind-turbine simulation.

Our wind-turbine LESs represent most of the relevant regimes during a diurnal cycle, including stable and convective conditions as well as the morning and evening conditions. The numerical results lay the groundwork for a variety of further applications over a wide range of scales and for flow over heterogeneous surfaces and hilly terrain. These simulations can be conducted with little extra effort, because our numerical setup of the ABL simulations, our wind-turbine model, and our interface between the ABL and wind-turbine 
simulations are all implemented in the geophysical flow solver EULAG. In EULAG, the governing equations are formulated and numerically solved in generalized curvilinear coordinates. Within the scope of this work, all implementations are also performed in generalized curvilinear coordinates. This feature in combination with the non-oscillatory forward-in-time differencing makes EULAG well-suited to simulate the interaction of a wind turbine with flow over hilly terrain. The additional implemented immersed boundary technique further allows numerical simulations over heterogeneous surfaces characterized by roughness elements.

As a first approach towards a more realistic representation of the surface conditions, the idealized ABL simulations were repeated for flow over spatiallydistributed cubed obstacles corresponding to a surface density of $25 \%$. This setup is a relevant scenario, as wind turbines should preferably be placed in suburban areas in the future to limit energy transfer and storage. The main difference to the results of the homogeneous ABL simulation is the occurrence of nearly identical low-level wind profiles during the day and night. They reveal almost no vertical and directional shear of the horizontal wind components across the levels of the wind-turbine rotor. However, at lower levels, the increase in shear leads to an enhancement of the mechanical TKE production. The resulting turbulent eddies lead to increased turbulent mixing counteracting the formation of the night-time Ekman spiral. This crucial difference of the simulated flow between homogeneous and heterogeneous surface conditions at night is an important finding and impacts the wake structure of the wind turbine.

The synchronized turbulent inflow for the heterogeneous wind-turbine simulations was performed in the same way as for the homogeneous runs. As expected, the resulting wakes under convective and the stable conditions are very similar to each other regarding the absolute wake deflection and the vertical gradient. During the day, the flow in the wake recovers more rapidly in contrast to the corresponding homogeneous runs. The simulated wakes produced for the nighttime situation differ for the simulated heterogeneous and homogeneous surface conditions. The heterogeneous run reveals a less pronounced velocity deficit and the enhanced entrainment, caused by shear-induced mixing, leads to a more rapid recovery of the ambient flow. Thus, the actual wake response under night-time conditions depends crucially on the combination of thermal stratification and mechanically-produced turbulence due to the flow over a given surface. In conclusion, wind speed, wind shear, and the level of atmospheric turbulence are the atmospheric variables with a dominant impact on the wake structure, but the heterogeneous surface has an additional crucial impact on the wake structure as well.

Acknowledgements This research was performed as part of the LIPS project, funded by the Federal Ministry of Economic Affairs and Energy by a resolution of the German Federal Parliament (support code 0325518). The authors gratefully acknowledge the Gauss Centre for Supercomputing e.V. (www.gauss-center.eu) for funding this project by providing 
818 computing time on the GCS Supercomputer SuperMUC at Leibniz Supercomputing Centre 819 (LRZ, www.lrz.de) 


\section{References}

Abkar M, Porté-Agel F (2014) The effect of atmospheric stability on wind-turbine wakes: A large-eddy simulation study. J Phys Conf Ser 524(1):012,138

Abkar M, Sharifi A, Porté-Agel F (2016) Wake flow in a wind farm during a diurnal cycle. J Turbul 17(4):420-441

Aitken ML, Kosović B, Mirocha JD, Lundquist JK (2014) Large eddy simulation of wind turbine wake dynamics in the stable boundary layer using the Weather Research and Forecasting Model. J Renew Sust Energy 6(3):033,137

Baker RW, Walker SN (1984) Wake measurements behind a large horizontal axis wind turbine generator. Solar Energy 33(1):5-12

Balsley BB, Svensson G, Tjernström M (2008) On the scale-dependence of the gradient Richardson number in the residual layer. Boundary-Layer Meteorol 127(1):57-72

Basu S, Vinuesa JF, Swift A (2008) Dynamic LES modeling of a diurnal cycle. J Appl Meteorol Clim 47(4):1156-1174

Beare RJ (2008) The role of shear in the morning transition boundary layer. Boundary-Layer Meteorol 129(3):395-410

Beare RJ, Macvean MK, Holtslag AAM, Cuxart J, Esau I, Golaz JC, Jimenez MA, Khairoutdinov M, Kosović B, Lewellen D, Lund TS, Lundquist JK, Mccabe A, Moene AF, Noh Y, Raasch S, Sullivan P (2006) An intercomparison of large-eddy simulations of the stable boundary layer. Boundary-Layer Meteorol 118(2):247-272

Belcher S, Jerram N, Hunt J (2003) Adjustment of a turbulent boundary layer to a canopy of roughness elements. J Fluid Mech 488:369-398

Bhaganagar K, Debnath M (2014) Implications of stably stratified atmospheric boundary layer turbulence on the near-wake structure of wind turbines. Energies 7(9):5740-5763

Bhaganagar K, Debnath M (2015) The effects of mean atmospheric forcings of the stable atmospheric boundary layer on wind turbine wake. J Renew Sust Energy 7(1):013,124

Blay-Carreras E, Pino D, Vilà-Guerau de Arellano J, van de Boer A, De Coster O, Darbieu C, Hartogensis O, Lohou F, Lothon M, Pietersen H (2014) Role of the residual layer and large-scale subsidence on the development and evolution of the convective boundary layer. Atmos Chem Phys 14(9):45154530

Bou-Zeid E, Meneveau C, Parlange MB (2004) Large-eddy simulation of neutral atmospheric boundary layer flow over heterogeneous surfaces: Blending height and effective surface roughness. Water Resour Res 40(2)

Calaf M, Meneveau C, Meyers J (2010) Large eddy simulation study of fully developed wind-turbine array boundary layers. Phys Fluids 22(1):015,110

Calaf M, Higgins C, Parlange MB (2014) Large wind farms and the scalar flux over an heterogeneously rough land surface. Boundary-Layer Meteorol 153(3):471-495 
Carlson MA, Stull RB (1986) Subsidence in the nocturnal boundary layer. J Clim Appl Meteorol 25(8):1088-1099

Chamorro LP, Porté-Agel F (2010) Effects of thermal stability and incoming boundary-layer flow characteristics on wind-turbine wakes: A wind-tunnel study. Boundary-Layer Meteorol 136(3):515-533

Conzemius R, Fedorovich E (2007) Bulk models of the sheared convective boundary layer: Evaluation through large eddy simulations. J Atmos Sci 64(3):786-807

Deardorff JW (1974a) Three-dimensional numerical study of the height and mean structure of a heated planetary boundary layer. Boundary-Layer Meteorol 7(1):81-106

Deardorff JW (1974b) Three-dimensional numerical study of turbulence in an entraining mixed layer. Boundary-Layer Meteorol 7(2):199-226

Dörenkämper M, Witha B, Steinfeld G, Heinemann D, Kühn M (2015) The impact of stable atmospheric boundary layers on wind-turbine wakes within offshore wind farms. J Wind Eng Indust Aerodyn 144:146-153

Dörnbrack A, Schumann U (1993) Numerical simulation of turbulent convective flow over wavy terrain. Boundary-Layer Meteorol 65(4):323-355

Doyle JD, Gaberšek S, Jiang Q, Bernardet L, Brown JM, Dörnbrack A, Filaus E, Grubišic V, Kirshbaum DJ, Knoth O, Koch S (2011) An intercomparison of T-REX mountain-wave simulations and implications for mesoscale predictability. Mon Weather Rev 139:2811-2831

Emeis S (2013) Wind Energy Meteorology: Atmospheric Physics for Wind Power Generation. Springer-Verlag, Berlin Heidelberg, Germany

Emeis S (2014) Current issues in wind energy meteorology. Meteorol Appl 21(4):803-819

Englberger A, Dörnbrack A (2017) Impact of neutral boundary-layer turbulence on wind-turbine wakes: A numerical modelling study. Boundary-Layer Meteorol 162:427-449

Fedorovich E, Nieuwstadt F, Kaiser R (2001) Numerical and laboratory study of a horizontally evolving convective boundary layer. part I: Transition regimes and development of the mixed layer. J Atmos Sci 58(1):70-86

Fröhlich J (2006) Large Eddy Simulation turbulenter Strömungen. Teubner Verlag / GWV Fachverlage GmbH, Wiesbaden, 414 pp

Gisinger S, Dörnbrack A, Schröttle J (2015) A modified Darcy's Law. Theor Comput Fluid Dyn 29(4):343

Gomes VMMGC, Palma JMLM, Lopes AS (2014) Improving actuator disk wake model. In: The science of making torque from wind. Conference series, vol 524, p 012170.

Grimsdell AW, Angevine WM (2002) Observations of the afternoon transition of the convective boundary layer. J Appl Meteorol 41(1):3-11

Hancock P, Zhang S (2015) A wind-tunnel simulation of the wake of a large wind turbine in a weakly unstable boundary layer. Boundary-Layer Meteorol 156(3):395-413

Hancock PE, Pascheke F (2014) Wind-tunnel simulation of the wake of a large wind turbine in a stable boundary layer: Part 2, the wake flow. Boundary- 
Layer Meteorol 151(1):23-37

Hansen KS, Barthelmie RJ, Jensen LE, Sommer A (2012) The impact of turbulence intensity and atmospheric stability on power deficits due to wind turbine wakes at Horns Rev wind farm. Wind Energy 15(1):183-196

Iungo GV, Porté-Agel F (2014) Volumetric lidar scanning of wind turbine wakes under convective and neutral atmospheric stability regimes. J Atmos Ocean Technol 31(10):2035-2048

Kang SL, Lenschow DH (2014) Temporal evolution of low-level winds induced by two-dimensional mesoscale surface heat-flux heterogeneity. BoundaryLayer Meteorol 151(3):501-529

Kang SL, Lenschow D, Sullivan P (2012) Effects of mesoscale surface thermal heterogeneity on low-level horizontal wind speeds. Boundary-Layer Meteorol 143(3):409-432

Kataoka H, Mizuno M (2002) Numerical flow computation around aeroelastic 3D square cylinder using inflow turbulence. Wind Struct 5:379-392

Kelley CL, Ennis BL (2016) Swift site atmospheric characterization. Tech. rep., Sandia National Laboratories (SNL-NM), Albuquerque, NM, United States

Kühnlein C, Smolarkiewicz PK, Dörnbrack A (2012) Modelling atmospheric flows with adaptive moving meshes. J Comput Phys 231(7):2741-2763

Kumar V, Kleissl J, Meneveau C, Parlange MB (2006) Large-eddy simulation of a diurnal cycle of the atmospheric boundary layer: Atmospheric stability and scaling issues. Water Resour Res 42(6)

Lu H, Porté-Agel F (2011) Large-eddy simulation of a very large wind farm in a stable atmospheric boundary layer. Phys Fluids 23(6):065,101

Magnusson M, Smedman A (1994) Influence of atmospheric stability on wind turbine wakes. Wind Eng 18(3):139-152

Mahrt L (1998) Nocturnal boundary-layer regimes. Boundary-Layer Meteorol 88(2):255-278

Margolin LG, Smolarkiewicz PK, Sorbjan Z (1999) Large-eddy simulations of convective boundary layers using nonoscillatory differencing. Phys D Nonlin Phenom 133(1):390-397

Medici D, Alfredsson PH (2006) Measurements on a wind turbine wake: 3D effects and bluff body vortex shedding. Wind Energy 9(3):219-236

Millward-Hopkins J, Tomlin A, Ma L, Ingham D, Pourkashanian M (2012) The predictability of above roof wind resource in the urban roughness sublayer. Wind Energy 15(2):225-243

Mirocha JD, Kosović B, Aitken ML, Lundquist JK (2014) Implementation of a generalized actuator disk wind turbine model into the Weather Research and Forecasting model for large-eddy simulation applications. J Renew Sust Energy 6(1):013,104

Mirocha JD, Rajewski DA, Marjanovic N, Lundquist JK, Kosović B, Draxl C, Churchfield MJ (2015) Investigating wind turbine impacts on near-wake flow using profiling lidar data and large-eddy simulations with an actuator disk model. J Renew Sust Energy 7(4):043,143 
Moeng CH, Sullivan PP (1994) A comparison of shear-and buoyancy-driven planetary boundary layer flows. J Atmos Sci 51(7):999-1022

Naughton JW, Heinz S, Balas M, Kelly R, Gopalan H, Lindberg W, Gundling C, Rai R, Sitaraman J, Singh M (2011) Turbulence and the isolated wind turbine. In: 6th AIAA Theoretical Fluid Mechanics Conference, Honolulu, Hawaii, pp 1-19.

Nieuwstadt FT (1984) The turbulent structure of the stable, nocturnal boundary layer. J Atmos Sci 41(14):2202-2216

Pino D, Vilà-Guerau de Arellano J, Duynkerke PG (2003) The contribution of shear to the evolution of a convective boundary layer. J Atmos Sci 60(16):1913-1926

Pino D, Jonker HJ, De Arellano JVG, Dosio A (2006) Role of shear and the inversion strength during sunset turbulence over land: characteristic length scales. Boundary-Layer Meteorol 121(3):537-556

Porté-Agel F, Lu H, Wu YT (2010) A large-eddy simulation framework for wind energy applications. in: The Fifth International Symposium on Computational Wind Engineering

Prusa JM, Smolarkiewicz PK, Wyszogrodzki AA (2008) EULAG, a computational model for multiscale flows. Comput Fluids 37(9):1193-1207

Sathe A, Mann J, Barlas T, Bierbooms W, Bussel G (2013) Influence of atmospheric stability on wind turbine loads. Wind Energy 16(7):1013-1032

Schmidt H, Schumann U (1989) Coherent structure of the convective boundary layer derived from large-eddy simulations. J Fluid Mech 200:511-562

Schröttle J, Dörnbrack A (2013) Turbulence structure in a diabatically heated forest canopy composed of fractal Pythagoras trees. Theor Comput Fluid Dyn pp 1-23

Smolarkiewicz PK, Charbonneau P (2013) EULAG, a computational model for multiscale flows: An MHD extension. J Comput Phys 236:608-623

Smolarkiewicz PK, Dörnbrack A (2008) Conservative integrals of adiabatic durran's equations. Int J Numer Methods Fluids 56:1513-1519

Smolarkiewicz PK, Margolin LG (1993) On forward-in-time differencing for fluids: extension to a curviliniear framework. Mon Weather Rev 121:18471859

Smolarkiewicz PK, Margolin LG (1998) MPDATA: A finite-difference solver for geophysical flows. J Comput Phys 140(2):459-480

Smolarkiewicz PK, Prusa JM (2002) Forward-in-time differencing for fluids: simulation of geophysical turbulence. In: Turbulent Flow Computation, Kluwer Academic Publishers, Boston, USA, pp 279-312

Smolarkiewicz PK, Prusa JM (2005) Towards mesh adaptivity for geophysical turbulence: continuous mapping approach. Int J Numer Methods Fluids 47:789-801

Smolarkiewicz PK, Pudykiewicz JA (1992) A class of semi-Lagrangian approximations for fluids. J Atmos Sci 49:2082-2096

Smolarkiewicz PK, Sharman R, Weil J, Perry SG, Heist D, Bowker G (2007) Building resolving large-eddy simulations and comparison with wind tunnel experiments. J Comput Phys 227:633-653 
Sorbjan Z (1996) Effects caused by varying the strength of the capping inversion based on a large eddy simulation model of the shear-free convective boundary layer. J Atmos Sci 53(14):2015-2024

Sorbjan Z (1997) Decay of convective turbulence revisited. Boundary-Layer Meteorol 82(3):503-517

Sorbjan Z (2007) A numerical study of daily transitions in the convective boundary layer. Boundary-Layer Meteorol 123(3):365-383

Stull RB (1988) An Introduction to Boundary Layer Meteorology. Kluwer Academic, Dordecht, Netherlands

Sullivan PP, Moeng CH, Stevens B, Lenschow DH, Mayor SD (1998) Structure of the entrainment zone capping the convective atmospheric boundary layer. J Atmos Sci 55(19):3042-3064

Tian W, Ozbay A, Yuan W, Sarakar P, Hu H (2013) An experimental study on the performances of wind turbines over complex terrain. In: 51st AIAA Aerospace Sciences Meeting including the New Horizons Forum and Aerospace Exposition, 07-10 January 2013, Grapevine, Texas, USA, pp 1-14

Vanderwende B, Lundquist JK (2012) The modification of wind turbine performance by statistically distinct atmospheric regimes. Environ Res Lett 7(3):034,035

Vollmer L, Steinfeld G, Heinemann D, Kühn M (2016) Estimating the wake deflection downstream of a wind turbine in different atmospheric stabilities: An LES study. Wind Energy Sci 1(2):129-141

von Larcher T, Dörnbrack A (2014) Numerical simulations of baroclinic driven flows in a thermally driven rotating annulus using the immersed boundary method. Meteorol Z pp 1-12

Wedi NP, Smolarkiewicz PK (2004) Extending Gal-Chen and Somerville terrain-following coordinate transformation on time-dependent curvilinear boundaries. J Comput Phys 193:1-20

Wedi NP, Smolarkiewicz PK (2006) Direct numerical simulation of the PlumbMcEwan laboratory analog of the QBO. J Atmos Sci 63:3226-3252

Wehner B, Siebert H, Ansmann A, Ditas F, Seifert P, Stratmann F, Wiedensohler A, Apituley A, Shaw R, Manninen H, Kulmala M (2010) Observations of turbulence-induced new particle formation in the residual layer. Atmos Chem Phys 10(9):4319-4330

Wharton S, Lundquist JK (2012) Atmospheric stability affects wind turbine power collection. Environ Res Lett 7(1):014,005

Wieringa J (1976) An objective exposure correction method for average wind speeds measured at a sheltered location. Q J R Meteorol Soc 102(431):241253

Witha B, Steinfeld G, Heinemann D (2014) Wind energy - Impact of turbulence, vol Spring 2012, Oldenburg, Germany, Springer, chap High-resolution offshore wake simulations with the LES model PALM, pp pp 175-181

Wu YT, Porté-Agel F (2011) Large-eddy simulation of wind-turbine wakes: Evaluation of turbine parametrisations. Boundary-Layer Meteorol 138:345366 
Wu YT, Porté-Agel F (2012) Atmospheric turbulence effects on wind-turbine wakes: An LES Study. Energies 5(12):5340-5362

Zhang W, Markfort CD, Porté-Agel F (2012) Near-wake flow structure downwind of a wind turbine in a turbulent boundary layer. Exp Fluids 52:12191235

Zhang W, Markfort CD, Porté-Agel F (2013) Wind-turbine wakes in a convective boundary layer: A wind-tunnel study. Boundary-Layer Meteorol 146:161-179 